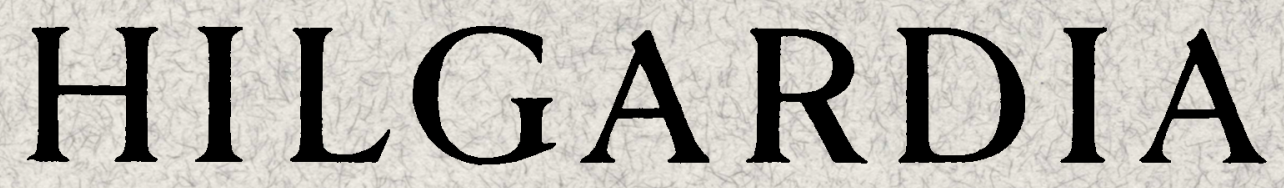

A Journal of Agricultural Science Published by the California Agricultural Experiment Station

\title{
DISPERSAL BEHAVIOR OF THE FIRST INSTAR NYMPHS OF THE WOOLLY APPLE APHID
}

\author{
STANLEY C. HOYT \\ and \\ HAROLD F. MADSEN
}






A Journal of Agricultural Science Published by

the California Agricultural Experiment Station

VOL. 30

DECEMBER, 1960

No. 10

\section{DISPERSAL BEHAVIOR OF THE FIRST INSTAR NYMPHS OF THE WOOLLY APPLE APHID}

\author{
STANLEY C. HOYT ${ }^{2}$ and HAROLD F. MADSEN ${ }^{3}$
}

\section{INTRODUCTION}

THE WOOLLY APPLE APHID, Eriosoma lanigerum (Hausmann), has been known for over 150 years as a pest of apple trees that causes a loss in tree vigor and that produces honeydew which drips on the fruit. Only in recent years has it been considered a pest of the fruit itself. In 1942, Essig ${ }^{4}$ reported its presence in the cores of Yellow Newtown Pippin apples from the Watsonville area of California. This condition was reported again in 1954 by Madsen, Borden, and Koch. It was found that these apples have an opening through the calyx into the core of the fruit. The aphids can enter this small opening when they are first instar nymphs and can establish colonies inside the fruit. Almost the entire crop of this variety of apple is used for canning. During the canning process the cores are removed mechanically, but the coring machines are not always accurate, and portions of the core may escape removal. If aphid colonies are present in those cores which are not removed, insects or insect fragments would be contained in the finished product.

In the course of investigations on preventing the presence of aphids in the cores of the fruit, it was felt that some attention should be given to when and why the aphids moved into the fruit. In addition, woolly apple aphids were observed to be continually moving up and down the tree between limbs and roots. For these reasons, studies were undertaken of the time and direction of the movements, the number of aphids involved, and some of the factors controlling the movement.

\section{TAXONOMY}

Eriosoma lanigerum is a member of the family Aphidae, subfamily Eriosomatinae, according to Palmer (1952). The species was first described by Hausmann in 1802 as Aphis lanigera. Since that time it has been given several generic and specific names by various authors. A complete synonomy

\footnotetext{
${ }^{1}$ Submitted for publication November, 1959.

${ }^{2}$ Formerly Research Assistant in Entomology in the Experiment Station, Berkeley; now Associate Entomologist in the Washington State University, Tree Fruit Experiment Station, Wenatchee, Washington.

${ }^{3}$ Associate Entomologist in the Experiment Station, Berkeley.

"See "Literature Cited" for citations referred to in the text by author and date.
} 
and a reproduction of Hausmann's original description may be found in Baker (1915).

Although $E$. lanigerum is difficult to distinguish from other members of the genus on the basis of morphological characters alone, it is the only one reported to attack apple in California. Heriot (1938) stated that although apple is a common host to both $E$. lanigerum and $E$. crataegi (Oestlund), $E$. crataegi did not occur on apple in British Columbia. An examination of the literature, however, showed no reference to $E$. crataegi on apple. Patch (1938) lists its only host as Crataegus spp. If $E$. crataegi does not occur on apple, then the only member of the genus which does is E. lanigerum. At any rate, Heriot (1938) states that these two species can be separated by the differences in the wax glands and cornicles.

Descriptions of $E$. lanigerum and related species may be found in Baker (1915) and Palmer (1952). Baker's paper includes descriptions of the different instars and forms of the woolly apple aphid.

All of the aphids used in this study were taken from apple. Several apterous and a few alate specimens were examined and determined to be Eriosoma lanigerum.

\section{LIFE HISTORY}

In the eastern United States, the primary host of the woolly apple aphid is American elm, Ulmus americana, according to Patch (1912). In California, as is true in most of the rest of the world, it has lost the ability to establish on elm and it is confined to its alternate hosts. In these areas the aphid is capable of spending its entire life on apple.

In California, the aphid overwinters on the limbs or roots of apple; and, where temperatures are mild, it is capable of reproducing throughout the entire year. The newly produced young do not necessarily begin to feed as soon as they are deposited, but move up or down the tree, establishing new colonies or joining old ones. Reproduction is entirely parthenogenetic, apterous viviparous females producing apterous viviparous females. In the fall, a small number of alate females are produced, the fate of which will be noted later. Numerous generations are produced during the course of a year, the number depending to a great extent on the temperature.

The principal method of spread from orchard to orchard under California conditions is on nursery stock. From tree to tree the aphids are dispersed mainly by crawling, by wind, or by human agencies.

\section{LITERATURE REVIEW}

There has been a wide variety of information published on the woolly apple aphid, but very little referring to local movements by the apterous forms. Among those papers which do mention movement, there is some contradiction as to when and why it takes place.

Dumbleton and Jeffreys (1938), working in New Zealand, stated that there was no definite autumn movement to the roots. According to Lohrenz (1911), the aphids had little tendency to wander, but he believed that they moved to the roots when it was hot. Theobald (1920) found that there was an upward movement in the early summer and a movement from the limbs to the roots in the fall. Patch (1913) suggested that the aphids moved from 
the roots when the roots were demolished. In her 1912 paper, Patch stated that mature aphids moved to new sites when crowded, and that young were deposited that sought the roots. On the other hand, Froggatt (1903) stated that young aphids wandered in an aimless manner.

Bodenheimer (1947), working in Palestine, found that the aerial and root colonies developed independently, with little movement between them. The root colonies were formed or increased by aphids crawling from dropped leaves or fruit. He found no indication that they were formed or depleted by vertical movements.

A paper by Schoene and Underhill (1935) from Virginia was the only extensive piece of work on local movements by the apterous nymphs. They found that the first few young tended to remain near an isolated female, but as the size of the colony increased the nymphs would wander. They could move over the trees or ground for two or three days before settling down to feed, but once they started feeding there was little tendency to wander. They were most active from 2:00 to 6:00 p.m., being capable of moving 1 foot in 5 minutes on smooth surfaces. The nymphs sought shade as the temperature rose. When they were trapped on sticky bands, most of the aphids were found on the north side of the tree. These workers also found that the wind direction influenced the direction of movement over the surface of the ground.

\section{LABORATORY STUDIES}

Methods and Materials.-In the greenhouses at Berkeley a constant supply of woolly apple aphids was maintained. An initial group of 10 seedling apple trees was infested with first instar nymphs of the woolly apple aphid collected at Watsonville, California, by pouring approximately 100 aphids onto the new leaves at the top of the tree. The trees were watered through saucers under the pots, to prevent the soil from becoming too damp; this allowed colonies to form on the roots.

Approximately every two weeks, 10 trees were infested with first instar nymphs from the previously infested trees. These new trees were kept separated from the old trees, to keep parasitism and predation at a low level.

Large numbers of first instar nymphs of the aphid were collected rapidly by holding an infested tree in a horizontal position over a piece of paper and striking the tree sharply. The aphids which dropped to the paper were then aspirated into vials in the desired numbers.

For trapping the aphids in the laboratory, cellophane tape bands onehalf inch wide with very thin strips of a polybutene material in the center of the band were used. These polybutenes are highly sticky materials which trap the aphids coming into contact with them.

Infestation of a Small Tree.-By infesting a tree with a single aphid, the course of the subsequent infestation could be followed. Many of the first individuals produced tended to establish near the parent female, as was also reported by Schoene and Underhill (1935). However, even among those first few aphids deposited, some tended to move away. As the area around the first female became crowded, the tendency for the first instar nymphs to move away became greater. They moved up or down the tree, settling where the old colonies were not so crowded or forming new colonies. In extremely crowded 
colonies, many aphids dropped to the ground. After they were on the ground, there seemed to be little attraction back to the tree, but more of a tendency to wander. In the greenhouse, this wandering appeared to be random, but in direct sunlight the aphids moved away from the sun. Some of the aphids moved into the soil and infested the roots, building up small colonies. If the colonies above the soil surface were destroyed, new colonies were formed within a few weeks by aphids moving up from these root colonies.

From the above it seems that the factors which affect the amount of movement are the number of aphids deposited, the amount of crowding within the colony, and the availability of space for the colony.



Fig. 1. Diagram of the apparatus used to establish temperature gradients.

Effect of Temperature on Movement.-The following experiments were designed to test the effect of various temperature ranges on the movement of the woolly apple aphid. The results of preliminary experiments showed that these aphids would not congregate and remain at some preferred temperature. It was therefore necessary to use the cellophane tape sticky bands to trap the aphids as they moved.

To establish temperature gradients and test their effects on the direction of the woolly apple aphid movements, the equipment diagrammed in figure 1 was used. The aluminum foil sand packet was heated in a drying oven and retained heat for a period long enough to run one or more tests. By its wedge shape, it established a portion of the gradient of temperatures. By varying the height of the supports, minor adjustments in temperature were made. At the center of the pine stick at the position marked " 3 " is an "X." Two inches from either end of the stick, at the points marked " 1 " and " 5 ," cellophane tape sticky bands were placed. Not shown in this diagram, but parallel to this stick, was another stick which supported 5 thermocouples 3 inches apart, one at each point marked " 1 " through " 5 ." Where temperature ranges of $55^{\circ}$ to $65^{\circ} \mathrm{F}$ or lower were desired, this apparatus was placed in an icebox. 
This apparatus gave a gradient of temperature from point " 1 " above the ice, increasing in warmth to point " 5 " at the thick end of the wedge. The temperatures along this gradient were measured and recorded at 3-inch intervals by the thermocouples and a recording potentiometer.

Approximately 100 aphids were collected in vials by the methods described above. When the desired temperature gradient was established, the lightproof box was removed, the aphids were introduced at the " $\mathrm{X}$ " on the stick by tapping gently on the vial, and the box was replaced.

Since aphids move at different speeds at different temperatures, the time allowed the aphids to move the 6 inches to the sticky bands was determined by the temperature. These times were determined by preliminary tests, and they represent a practical limit for nearly 100 per cent capture of the aphids remaining on the stick. When the mid-point of the range was $55^{\circ} \mathrm{F}$ or below, the experiment was run for 30 minutes. Above this temperature, the experiment was run for 20 minutes. The aphids trapped on the bands were counted under a dissecting microscope, and were recorded as the number moving toward the high temperature or the number moving toward the low temperature. Although approximately 100 first instar nymphs were introduced in all cases, an average of 51 were trapped, since some fell off and some failed to move the 6 inches.

Although it would have been desirable to maintain exactly the same temperature gradient and range in all replicates of an experiment, this was not practical with the equipment available. However, the range of the temperatures was generally close to $10^{\circ} \mathrm{F}$, although variations as high as $4^{\circ} \mathrm{F}$ from this figure occurred. If the range of the temperatures was only about $3^{\circ} \mathrm{F}$, the aphids did not respond to the temperature differences.

Since the gradients and the ranges of temperature showed some variation, the data were plotted in two figures, to show the relationship with the temperature extremes of each range. Figure 2 shows the relationship between the temperature at the warm end of the gradient and the percentage of the aphids trapped at the low temperaure end. Figure 3 shows the relationship between the temperature at the cold end of the gradient and the percentage of aphids trapped at the cold end. Each point in the figures represents a replicate using 100 aphids, with the percentages calculated from the number of aphids trapped in the bands. The temperatures in the figures represent an average at each point for the time of the experiment. In general, the temperature variation at each thermocouple position was approximately $1^{\circ} \mathrm{F}$, except at high temperatures, where a change of $3^{\circ}$ to $4^{\circ} \mathrm{F}$ during the experiment occurred in some cases.

An examination of figures 2 and 3 shows that when the high temperature of the gradient was above $70^{\circ} \mathrm{F}$, a high percentage of the aphids was trapped at the cold end of the gradient. This percentage increased as the temperature was increased. As the temperature at the warm end of the gradient was decreased to between $60^{\circ}$ and $70^{\circ} \mathrm{F}$, the movement was nearly equal in either direction. When the low temperature of the gradient was below $55^{\circ} \mathrm{F}$, more aphids were trapped at the high temperature end. If the temperature of the release point was below $50^{\circ} \mathrm{F}$, very few aphids moved the 6 inches to the bands. 


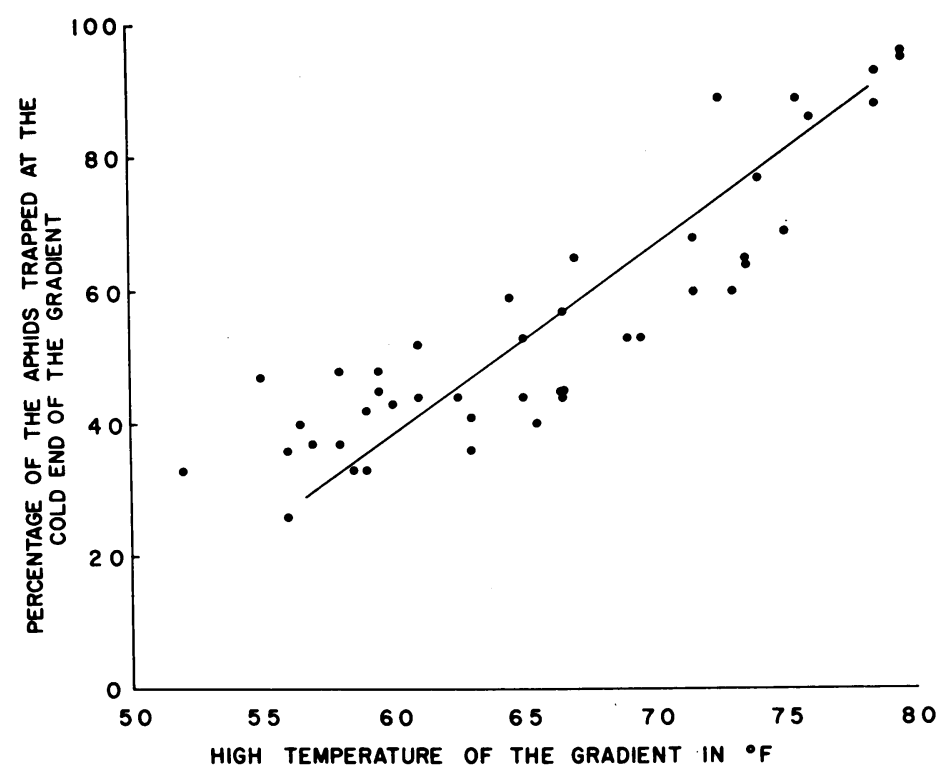

Fig. 2. Relationship between high temperature of the gradients and percentage of the aphids trapped at the cold end of the gradients $(R=0.89)$.

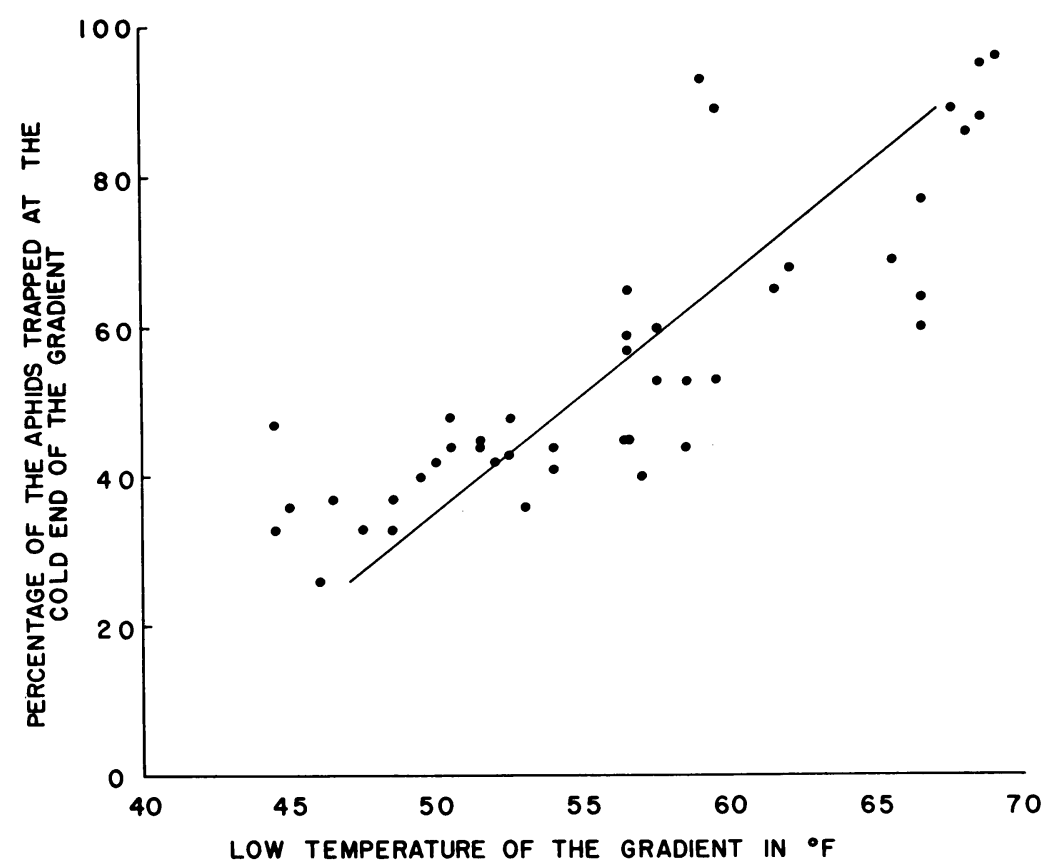

Fig. 3. Relationship between low temperature of the gradients and percentage of the aphids trapped at the cold end of the gradients $(R=0.83)$. 
This indicates that the aphids are repelled by high or low temperatures, but between $60^{\circ}$ and $70^{\circ} \mathrm{F}$ their movements are random. Temperatures below $50^{\circ} \mathrm{F}$ were not conducive to movement by the aphids.

A control experiment was also run in which equal temperatures were maintained at the five points. Results, shown in table 1 , indicate that in the control experiment, in contrast to the experiments with temperature gradients, aphid movement was approximately equal in both directions. With conditions equal at all points, a purely random movement occurred.

TABLE 1

MOVEMENT OF WOOLLY APPLE APHIDS IN THE ABSENCE OF LIGHT WHEN TEMPERATURES WERE EQUAL AT ALL POSITIONS

\begin{tabular}{|c|c|c|c|c|}
\hline \multicolumn{3}{|c|}{ Number of aphids trapped } & \multirow{2}{*}{$\begin{array}{l}\text { Percentage at } \\
\text { position } 1\end{array}$} & \multirow{2}{*}{$\underset{\left({ }^{\circ} F\right)}{\text { Temperature }}$} \\
\hline \multicolumn{2}{|c|}{ Position 1} & Position 5 & & \\
\hline & 31 & 31 & 50 & 70.0 \\
\hline & 37 & 25 & 60 & 74.0 \\
\hline & 27 & 40 & 40 & 75.0 \\
\hline & 32 & 38 & 46 & 74.5 \\
\hline & 22 & 25 & 47 & 73.5 \\
\hline & 27 & 18 & 60 & 73.5 \\
\hline & 22 & 26 & 46 & 74.0 \\
\hline & 23 & 24 & 49 & 72.0 \\
\hline & 22 & 14 & 61 & 47.0 \\
\hline & 11 & 9 & 55 & 50.0 \\
\hline & 26 & 33 & 44 & 54.5 \\
\hline Total & 280 & 283 & & \\
\hline Average & 25.5 & 25.7 & 50 & \\
\hline
\end{tabular}

The Effect of a Water Source on Movement.-Since ice was used for the cold temperatures in all of the temperature gradient trials, it was felt that a humidity gradient may have been present and may have had an additional effect on the direction of movement by the aphids. To test the possible effects of this on the direction of movement, an experiment similar to the control was set up. The temperatures were kept equal at all points, but water was placed in the tin can behind the barrier shown in figure 1 . The results of this experiment are listed in table 2 as the number of aphids moving toward and away from the water.

There was no significant difference between the number of aphids moving toward and the number moving away from the water. The water source thus had no apparent effect on the direction of movement taken by the aphids, and probably did not interfere with the experiments.

Effect of Light on Movement.-An attempt was made to determine the influence of light on the movement of aphids. Light was introduced by cutting a window 2 inches by 1 inch in one end of the light-proof box. To prevent air movement and changes in temperature, this window was covered with cellophane. Natural light or sunlight was used as the source of light in all cases, since the aphids seem to have a rather high threshold for light activation and do not respond very well to artificial light sources. 
TABLE 2

MOVEMENT OF WOOLLY APPLE APHIDS TOWARD AND AWAY FROM A WATER SOURCE IN THE ABSENCE OF LIGHT AND WITH NO TEMPERATURE GRADIENT*

\begin{tabular}{|c|c|c|c|c|}
\hline \multicolumn{3}{|c|}{ Number of aphids trapped } & \multirow{2}{*}{$\begin{array}{c}\text { Percentage } \\
\text { toward the } \\
\text { water }\end{array}$} & \multirow{2}{*}{$\begin{array}{c}\text { Temperature } \\
\left({ }^{\circ} F\right)\end{array}$} \\
\hline Tow & $\begin{array}{l}\text { rd the } \\
\text { ter }\end{array}$ & $\begin{array}{l}\text { Away from } \\
\text { the water }\end{array}$ & & \\
\hline & 31 & 44 & 41 & 61.5 \\
\hline & $\mathbf{5}$ & 18 & 22 & 62.5 \\
\hline & 36 & 22 & 62 & 70.0 \\
\hline & 25 & 30 & 45 & 70.0 \\
\hline & 36 & 42 & 46 & 70.0 \\
\hline & 36 & 48 & 43 & 70.5 \\
\hline & 27 & 36 & 43 & 70.5 \\
\hline & 27 & 23 & 54 & 70.5 \\
\hline & 41 & 35 & 54 & 70.5 \\
\hline & 47 & 39 & 55 & 70.5 \\
\hline Total & 311 & 337 & & \\
\hline Average & 31.1 & 33.7 & 48 & \\
\hline
\end{tabular}

* Data were analyzed by the " $t$ " test, and the difference was not significant at the 30 per cent level of confidence.

TABLE 3

MOVEMENTS OF WOOLLY APPLE APHIDS TOWARD AND AWAY FROM A LIGHT SOURCE WITH NO TEMPERATURE GRADIENT

\begin{tabular}{|c|c|c|c|c|}
\hline \multicolumn{3}{|c|}{ Number of aphids trapped } & \multirow{2}{*}{$\begin{array}{l}\text { Percentage } \\
\text { toward the } \\
\text { light }\end{array}$} & \multirow{2}{*}{$\underset{\left({ }^{\circ} F\right)}{\text { Temperature }}$} \\
\hline \multicolumn{2}{|c|}{$\begin{array}{l}\text { Moving toward } \\
\text { the light }\end{array}$} & \multirow{2}{*}{$\begin{array}{c}\text { Moving away } \\
\text { from the light }\end{array}$} & & \\
\hline \multirow[b]{11}{*}{ Average } & 17 & & 15 & 80.5 \\
\hline & 38 & 60 & 39 & 79.5 \\
\hline & 18 & 53 & 25 & 79.5 \\
\hline & 20 & 79 & 20 & 79.5 \\
\hline & 32 & 45 & 42 & 79.5 \\
\hline & 9 & 74 & 11 & 79.5 \\
\hline & 24 & 30 & 44 & 78.0 \\
\hline & 22 & 32 & 41 & 77.0 \\
\hline & 36 & 47 & 43 & 75.0 \\
\hline & 26 & 42 & 38 & 79.5 \\
\hline & 24.2 & 55.8 & 32 & 78.8 \\
\hline & 34 & 52 & 40 & 68.5 \\
\hline & 45 & 39 & 54 & 68.5 \\
\hline & 15 & 23 & 39 & 66.5 \\
\hline & 14 & 21 & 40 & 66.0 \\
\hline & 14 & 38 & 27 & 65.0 \\
\hline & 25 & 51 & 33 & 65.0 \\
\hline & 8 & 34 & 19 & 61.5 \\
\hline & 24 & 50 & 32 & 60.5 \\
\hline & 17 & 27 & 39 & 60.5 \\
\hline Average & 21.8 & 37.2 & 36 & 64.7 \\
\hline
\end{tabular}


In the first series of tests, the temperatures were kept equal at all points. Other conditions were the same as in the control experiment (table 1). The numbers of aphids trapped were recorded as those aphids moving toward or away from the light source.

Two series of replicates were run, one series at an average temperature of $78.8^{\circ} \mathrm{F}$, the other at an average temperature of $64.7^{\circ} \mathrm{F}$. The results of these tests are shown in table 3. A comparison of the two series shows that there is a greater tendency for the aphids to move away from the light source at high than at low temperatures.

TABLE 4

MOVEMENT OF WOOLLY APPLE APHIDS IN A TEMPERATURE GRADIENT, WITH A LIGHT SOURCE AT THE LOW TEMPERATURE END OF THE GRADIENT

\begin{tabular}{|c|c|c|c|c|c|c|c|c|}
\hline \multicolumn{3}{|c|}{ Number of aphids trapped } & \multirow{3}{*}{$\begin{array}{c}\text { Percentage } \\
\text { at } \\
\text { position } 1\end{array}$} & \multicolumn{5}{|c|}{ Temperature gradient $\left({ }^{\circ} F\right)$} \\
\hline \multirow{2}{*}{\multicolumn{2}{|c|}{$\begin{array}{l}\text { Low temp., light } \\
\text { Position } 1\end{array}$}} & \multirow{2}{*}{$\begin{array}{l}\text { High temp. } \\
\text { Position } 5\end{array}$} & & \multicolumn{5}{|c|}{ Thermocouple position } \\
\hline & & & & 1 & 2 & 3 & 4 & 5 \\
\hline & 36 & 31 & 54 & 68.0 & 73.0 & 76.0 & 77.0 & 80.5 \\
\hline & 58 & 24 & 71 & 68.0 & 72.5 & 75.0 & 79.0 & 81.5 \\
\hline & 47 & 34 & 58 & 67.0 & 71.0 & 73.0 & 79.0 & 79.5 \\
\hline & 65 & 34 & 65 & 66.5 & 69.5 & 72.0 & 76.0 & 81.0 \\
\hline & 45 & 48 & 48 & 67.0 & 72.0 & 74.5 & 75.0 & 77.0 \\
\hline & 40 & 45 & 47 & 68.0 & 70.0 & 71.5 & 73.5 & 77.5 \\
\hline & 44 & 35 & 56 & 66.5 & 71.5 & 73.5 & 76.0 & 78.0 \\
\hline & 54 & 36 & 60 & 66.5 & 69.0 & 71.0 & 735 & 76.0 \\
\hline & 58 & 49 & 54 & 66.5 & 71.5 & 73.0 & 75.0 & 76.0 \\
\hline Total...... & 447 & 336 & & & & & & \\
\hline Average... & 49.7 & 37.3 & 57 & 67.1 & 71.1 & 73.3 & 76.0 & 78.6 \\
\hline
\end{tabular}

By comparing this experiment with the control experiment (table 1), it is obvious that a considerable difference in the direction of movement occurs when a source of light is the only differing condition. It can be said that, at the temperatures tested, a high percentage of the aphids were negatively phototropic. In no ease, however, were 100 per cent of the aphids negatively phototropic.

Effects of Light and Temperature in Combination on Movement.-In the following two experiments, the same procedure described for the previous experiments was used, but temperature gradients were established in the presence of a light source. In the first series of tests, the window for the light source was placed at the low temperature end of the temperature gradient. The results of this experiment are shown in table 4.

Although a higher percentage of the aphids was trapped at the cooler end of the temperature gradient, this percentage was much lower than that recorded in table 5, an experiment where temperature gradients were present, but a light source was absent. In table 4, where the data show that the high temperatures of the gradient were slightly higher than those recorded in table 5, a greater percentage of the aphids would be expected to go to the cooler end due to the temperature alone. But the extremely strong effect of 
having the light source at the low temperature end caused a much greater percentage of the aphids than expected to move toward the higher temperatures. By comparing the data in tables 3 and 4 it can be seen that a higher percentage of the aphids moved toward the light source when it was accompanied by a cooler temperature than when temperatures were equal at all points.

TABLE 5

\section{MOVEMENT OF WOOLLY APPLE APHIDS IN TEMPERATURE GRADIENTS IN THE ABSENCE OF LIGHT}

\begin{tabular}{|c|c|c|c|c|c|c|c|c|}
\hline \multicolumn{3}{|c|}{ Number of aphids trapped } & \multirow{3}{*}{$\begin{array}{c}\text { Percentage } \\
\text { at } \\
\text { position } 1\end{array}$} & \multicolumn{5}{|c|}{ Temperature gradient $\left({ }^{\circ} F\right)$} \\
\hline \multirow{2}{*}{\multicolumn{2}{|c|}{$\begin{array}{l}\text { Low temp. } \\
\text { Position } 1\end{array}$}} & \multirow{2}{*}{$\begin{array}{l}\text { High temp. } \\
\text { Position 5 }\end{array}$} & & \multicolumn{5}{|c|}{ Thermocouple position } \\
\hline & & & & 1 & 2 & 3 & 4 & 5 \\
\hline & 72 & 3 & 96 & 69.0 & 71.0 & 74.5 & 77.5 & 79.5 \\
\hline & 59 & 8 & 88 & 68.5 & 70.5 & 73.0 & 75.0 & 78.5 \\
\hline & 55 & 3 & 95 & 68.5 & 70.0 & 73.5 & 76.5 & 79.5 \\
\hline & 54 & 9 & 86 & 68.0 & 69.5 & 72.5 & 75.0 & 76.0 \\
\hline & 59 & 7 & 89 & 67.5 & 69.0 & 71.5 & 73.5 & 75.5 \\
\hline & 63 & 18 & 77 & 66.5 & 68.5 & 71.0 & 72.5 & 74.0 \\
\hline & 46 & 26 & 64 & 66.5 & 67.5 & 70.0 & 71.5 & 73.5 \\
\hline & 31 & 21 & 60 & 66.5 & 68.0 & 70.5 & 71.5 & 73.0 \\
\hline & 42 & 19 & 69 & 65.5 & 68.0 & 71.0 & 72.5 & 75.0 \\
\hline Total...... & 481 & 114 & & & & & & \\
\hline Average... & 53.4 & 12.7 & 81 & 67.4 & 69.1 & 71.9 & 73.9 & 76.1 \\
\hline
\end{tabular}

TABLE 6

MOVEMENT OF WOOLLY APPLE APHIDS IN A TEMPERATURE GRADIENT WITH A LIGHT SOURCE AT THE HIGH TEMPERATURE END OF THE GRADIENT

\begin{tabular}{|c|c|c|c|c|c|c|c|c|}
\hline \multicolumn{3}{|c|}{ Number of aphids trapped } & \multirow{3}{*}{$\begin{array}{c}\text { Percentage } \\
\text { at } \\
\text { position } 1\end{array}$} & \multicolumn{5}{|c|}{ Temperature gradient $\left({ }^{\circ} F\right)$} \\
\hline \multirow{2}{*}{\multicolumn{2}{|c|}{$\begin{array}{l}\text { Low temp. } \\
\text { Position } 1\end{array}$}} & \multirow{2}{*}{$\begin{array}{c}\text { High temp., } \\
\text { light } \\
\text { Position } 5\end{array}$} & & \multicolumn{5}{|c|}{ Thermocouple position } \\
\hline & & & & 1 & 2 & 3 & 4 & 5 \\
\hline & 69 & 0 & 100 & 72.0 & 75.5 & 78.5 & 81.5 & 86.5 \\
\hline & 46 & 10 & 82 & 72.0 & 75.0 & 78.0 & 79.5 & 83.5 \\
\hline & 52 & 15 & 78 & 69.0 & 73.0 & 75.0 & 76.0 & 79.5 \\
\hline & 66 & 17 & 80 & 68.5 & 72.5 & 74.0 & 76.0 & 77.5 \\
\hline & 73 & 1 & 99 & 67.5 & 73.5 & 75.5 & 78.0 & 81.0 \\
\hline & 89 & 14 & 86 & 66.5 & 72.0 & 74.5 & 75.5 & 79.5 \\
\hline & 84 & 8 & 91 & 67.5 & 72.0 & 73.5 & 75.5 & 77.5 \\
\hline & 68 & 12 & 85 & 66.5 & 72.0 & 74.0 & 76.0 & 78.5 \\
\hline Total. & 547 & 77 & & & & & & \\
\hline Average... & 68.4 & 9.6 & 88 & 68.7 & 73.2 & 75.4 & 77.3 & 80.4 \\
\hline
\end{tabular}

In the next experiment, the light source was placed at the high temperature end of the temperature gradient. The results of this experiment are shown in table 6 .

By examining the data in tables 5 and 6 , a small difference in the percentage of aphids trapped at the low temperature is observed. Since the 
average temperature range is somewhat higher in table 6 , it is felt that this difference is not all due to a negative phototropism. At any rate, an extremely high percentage of aphids are repelled by light and high temperature in combination.

By comparing the data in tables 3 and 6 it can be seen that the introduction of the temperature gradient caused a change, from 32 per cent moving toward the light with no temperature effect, to only 12 per cent moving toward the light with a temperature effect.

These experiments on the effects of temperature and light on woolly apple aphid movements indicate that high temperatures or a light source repel the aphids (or, that low temperatures and darkness attract the aphids). When these two factors are acting together, they increase or decrease their individual effects, depending on their interrelationships. Thus, a light source combined with high temperatures is more repellent than either factor alone, whereas a light source combined with low temperatures is less repellent than a light source alone, but is also less attractive than low temperatures alone.

Vertical Movement of Aphids in the Light and in the Dark.-An experiment was designed to test the effects of sunlight and of gravity on the vertical movement of the first instar nymphs of the woolly apple aphid. Owing to the larger numbers of aphids available in the field, a part of this experiment was carried out at Watsonville, California. This part is included with the laboratory studies because of the nature of the experiment and for convenience in the comparison of the data.

The procedure used was similar to that of the previous experiments, with the following differences: the stick upon which the aphids moved was held vertically rather than horizontally; and, where light was desired, the lightproof box was removed and direct sunlight was the source of light. Darkness again was obtained by the use of the light-proof box.

Fifty aphids were introduced at the midpoint of the stick at the " $X$ " while the stick was held in a horizontal position. When the aphids had gained a foothold, the stick was rotated to a vertical position and placed in a clay support. The aphids were then given 15 minutes to move the 6 inches up or down to the sticky bands. The aphids trapped by the bands were counted and listed as the numbers of aphids moving up or down. This test was replicated 8 times in the light and 8 times in the dark. The results of the experiment are listed in table 7 .

When the aphids were exposed to the light, 94.5 per cent of them were trapped moving down; when they were inside of the light-proof box, 80.5 per cent were trapped moving down. Even though the light caused a significant difference from the darkness with regard to downward movement, there was such a high percentage of aphids moving down in the dark that it does not seem likely that this movement was random, as was the case in the dark under uniform conditions of gravity (see table 1). This indicates that a positive geotropism was responsible for the high percentage of downward movement in the dark. The high percentage of downward movement in the light is probably related to a combination of positive geotropism and negative phototropism.

In the second series of tests conducted at Watsonville, 50 aphids moving 
up on the trunk of a tree were collected. These aphids were probably a few hours older than those collected in the laboratory, because they had moved away from their parent colonies. Also, their direction of movement had already been determined. The method of introduction of the aphids

TABLE 7

VERTICAL MOVEMENTS OF LABORATORY-COLLECTED

FIRST INSTAR WOOLLY APPLE APHIDS IN SUNLIGHT AND IN THE DARK*

\begin{tabular}{ll|c|c|c}
\hline \hline \multicolumn{3}{c}{ Number of aphids trapped } \\
\hline \multicolumn{2}{c}{ In the sunlight } & \multicolumn{2}{c}{ In the dark } \\
\hline \multicolumn{2}{c}{ Up } & Down & Up & Down \\
\hline & 5 & 34 & 7 & 24 \\
& 0 & 49 & 10 & 21 \\
& 5 & 40 & 4 & 21 \\
& 2 & 42 & 0 & 9 \\
& 0 & 36 & 4 & 27 \\
& 2 & 27 & 9 & 25 \\
Total & 1 & 39 & 7 & 31 \\
Percentage & 5.5 & 42 & 2 & 177 \\
& 18 & 309 & 43 & 80.5 \\
\hline
\end{tabular}

* The difference between the movement in the sunlight and in the dark was analyzed by the Chi-square test, and this difference was significant at the 0.1 per cent level of confidence.

TABLE 8

VERTICAL MOVEMENTS OF FIELD-COLLECTED UP-

WARD-MOVING FIRST INSTAR WOOLLY APPLE APHIDS IN SUNLIGHT AND IN THE DARK

\begin{tabular}{|c|c|c|c|c|}
\hline \multicolumn{5}{|c|}{ Number of aphids trapped } \\
\hline \multicolumn{3}{|c|}{ In the sunlight } & \multicolumn{2}{|c|}{ In the dark } \\
\hline & $\mathrm{Jp}$ & Down & Up & Down \\
\hline & 21 & 2 & 7 & 10 \\
\hline & 37 & 5 & 8 & 16 \\
\hline & 31 & 8 & 26 & 17 \\
\hline & 29 & 4 & 18 & 17 \\
\hline & 29 & 4 & 14 & 15 \\
\hline & 14 & 1 & 10 & 6 \\
\hline Total & 161 & 24 & 83 & 81 \\
\hline Percentage & 87 & 13 & 50.6 & 49.4 \\
\hline
\end{tabular}

and the time of each replicate were the same as in the previous series of tests. This test was replicated 6 times in the light and 6 times in the dark; results are listed in table 8 .

In the direct sunlight, 87 per cent of the aphids which were collected moving up continued to move up. In the absence of light, however, only 50.6 per cent of the aphids went up. This suggests that light was the stimulus 
which directed the movement of the aphids, and that the movement was random in the dark. It also indicates that, once a direction of movement toward light has been determined, the majority of the aphids will continue to move in that direction even if they are disturbed. This directional movement can be overcome by denying the aphids the light stimulus which is governing their movements.

Effect of Air Movement on Direction of Aphid Movement.-According to Schoene and Underhill (1935), wind affected the direction of movement

TABLE 9

EFFECT OF AIR MOVEMENT ON MOVEMENT OF FIRST INSTAR WOOLLY APPLE APHIDS

\begin{tabular}{|c|c|c|c|c|}
\hline & \multicolumn{4}{|c|}{ Number of aphids moving into various quadrants } \\
\hline & $\underset{\text { current }}{\text { Against air }}$ & $\begin{array}{l}\text { With air } \\
\text { current }\end{array}$ & $\begin{array}{c}\text { To the } \\
\text { left }\end{array}$ & $\begin{array}{l}\text { To the } \\
\text { right }\end{array}$ \\
\hline No air movement & $\begin{array}{r}7 \\
6 \\
10 \\
5 \\
5\end{array}$ & $\begin{array}{r}6 \\
10 \\
14 \\
8 \\
5\end{array}$ & $\begin{array}{l}6 \\
5 \\
8 \\
4 \\
2\end{array}$ & $\begin{array}{r}6 \\
8 \\
14 \\
6 \\
3\end{array}$ \\
\hline $\begin{array}{l}\text { Average } \ldots \ldots \ldots \ldots \ldots \ldots \ldots \ldots \ldots \ldots \\
\text { Percentage } \ldots \ldots \ldots \ldots \ldots \ldots \ldots \ldots \ldots\end{array}$ & $\begin{array}{l}6.6 \\
24\end{array}$ & $\begin{array}{ll}8.6 \\
31\end{array}$ & $\begin{array}{r}5 \\
18\end{array}$ & $\begin{array}{c}7.4 \\
27\end{array}$ \\
\hline With air movement & $\begin{array}{r}14 \\
11 \\
6 \\
7 \\
16 \\
7 \\
10 \\
13 \\
7 \\
11\end{array}$ & $\begin{array}{r}8 \\
14 \\
12 \\
8 \\
3 \\
12 \\
3 \\
10 \\
10 \\
11\end{array}$ & $\begin{array}{l}8 \\
6 \\
3 \\
5 \\
6 \\
1 \\
4 \\
5 \\
0 \\
1\end{array}$ & $\begin{array}{l}2 \\
1 \\
2 \\
2 \\
5 \\
1 \\
1 \\
2 \\
1 \\
2\end{array}$ \\
\hline $\begin{array}{l}\text { Average } \ldots \ldots \ldots \ldots \ldots \ldots \ldots \ldots \ldots \ldots \\
\text { Percentage } \ldots \ldots \ldots \ldots \ldots \ldots \ldots \ldots \ldots\end{array}$ & $\begin{array}{l}10.2 \\
40.6\end{array}$ & $\begin{array}{r}9.1 \\
36.3\end{array}$ & $\begin{array}{r}3.9 \\
15.5\end{array}$ & $\begin{array}{l}1.9 \\
7.6\end{array}$ \\
\hline
\end{tabular}

of woolly apple aphids on the surface of the ground. However, they did not describe the nature of this effect. That air movement affected the direction of movement of the aphids was confirmed by the authors in those tests run on smooth surfaces in the laboratory, but not by observations in the field on the surface of the ground.

Laboratory tests were run by setting a fan 10 feet from a 2-foot-square piece of plywood so that the air moved over the surface of the plywood. Taped to the plywood was a 10 -inch dise of paper divided into 4 equal pieshaped segments. The disc was oriented so that one quadrant was toward the fan and one away from it. Fifty aphids were introduced in the center of the disc. The aphids were then given 5 minutes to crawl to the edge of the disc. As soon as an aphid reached the edge of the disc it was removed, and the position of the segment from which it was taken was recorded. The results of the experiment are shown in table 9 . 
When there was no air movement, the number of aphids moving into each quadrant did not differ significantly from what was expected in a purely random dispersal. But when there was air movement, the majority of the aphids moved directly toward or away from the source. The difference between the response of the aphids with and without air movement was significant at the 1 per cent level of confidence by the chi-square test.

Observations of aphids moving on the surface of the ground in an orchard indicate that the movements are random. It is felt that wind can have only a momentary effect on the direction of movement of the aphids on these rough ground surfaces. It was necessary for the aphids to crawl over clods, into cracks, and over many other obstacles which caused the aphids to change their course continually. Also, wind is such a variable factor that if the aphids were to respond to its effect they would be reorienting themselves constantly. The movement of the aphids on such a rough surface appears to be directed more by the direction in which it is possible for them to move, or what might be termed the "easiest" route.

Number of Aphids Moving in the Light and in the Dark.-The purpose of this experiment was to determine the relative number of aphids moving in the light and in the dark. A tree approximately 3 years old with an infestation of aphids on the limbs and on the roots was used. A cellophane tape sticky band was placed on the trunk of the tree about 4 inches above the surface of the soil. Darkness was obtained by the use of a large light-proof box which was placed over the entire tree. Temperature and humidity were recorded by hygrothermographs inside and outside of the box.

Every 48 hours the tree was banded and placed either under daylight conditions or in the dark for a 48-hour period. The results of this experiment are shown in table 10. The temperature in the light and in the dark remained at approximately $68^{\circ} \mathrm{F}$, and the humidity inside of the light-proof box averaged 65 per cent, slightly higher than the 60 per cent recorded outside of the box.

It can be seen that, in this experiment, over 75 per cent of the total movement occurred in the light, even though the temperature and the length of time-in the light and dark were equal. This higher percentage of movement in the light occurred both in the upward and downward movement. The percentage might have been higher, but toward the end of the experiment most of the young aphids present were alatoid nymphs which remain in the colony.

Since temperatures and humidities were nearly equal in the light and in the dark, lack of light must have been responsible in some way for the decreased movement. Observation of the colonies indicated that many nymphs were deposited in the dark, but most of these tended to remain in the colonies until light was again present. This points out the importance of light as a stimulus to movement.

The Importance of Alates in Local Movements.-In the eastern United States, alates of the woolly apple aphid are important in spreading the species over long distances (Patch, 1912). In areas other than the eastern United States, however, winged aphids are unimportant in perpetuating the species (Brittain, 1936; Dumbleton and Jeffreys, 1938; Heriot, 1938; Venables, 1929). 
If placed on American elm outside of the eastern United States, alates occasionally will deposit sexual forms (Crane, Greenslade, Massee, and Tydeman, 1936). These sexual forms rarely mate; and even if they do mate, an egg is rarely deposited. Schoene and Underhill (1935) stated, however, that summer alates were reported occasionally to deposit apterous viviparae on apple in Europe and Turkestan.

\section{TABLE 10}

VERTICAL MOVEMENT OF WOOLLY APPLE APHIDS ON THE TRUNK OF AN APPLE TREE, UNDER NORMAL CONDITIONS OF LIGHT AND DARK AND WHEN THE TREE WAS COVERED BY A LIGHT-PROOF BOX

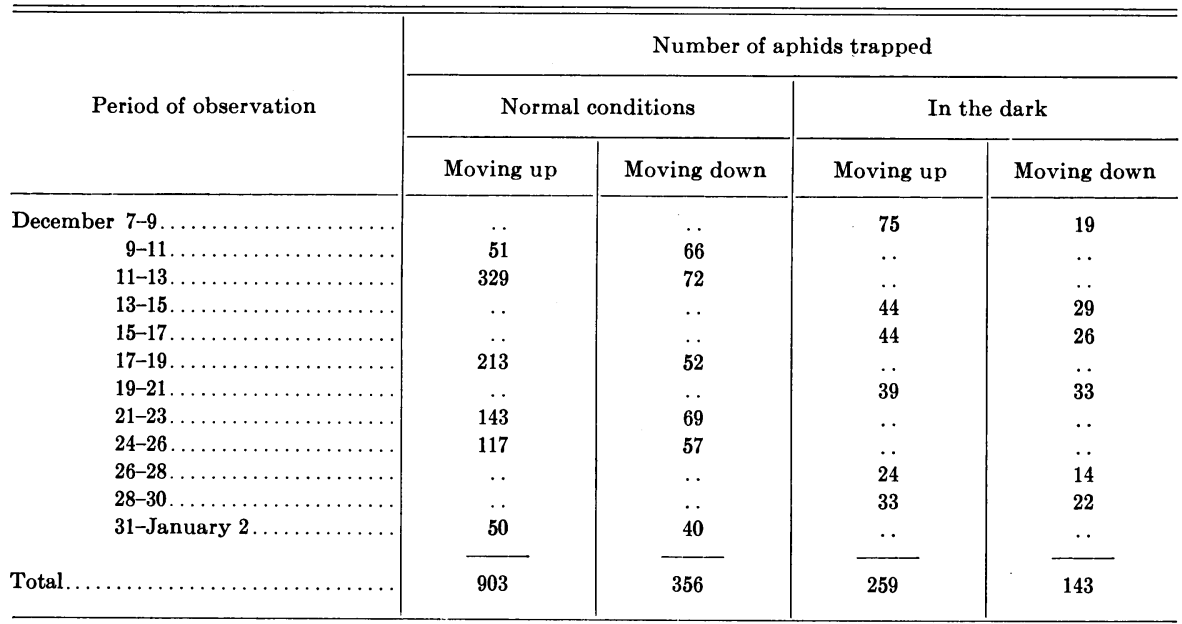

Over 100 alates of the woolly apple aphid were collected and caged on apple seedlings at various times during 1956 and 1957. All of the young deposited by the alates were sexual forms. These sexual forms did not mate and, therefore, may be considered unimportant in perpetuating the species in the greenhouse. Winged forms are not too common in California; and since the alates tested did not deposit any apterous viviparous females, it seems likely that such production as reported in Europe and Turkestan (Schoene and Underhill, 1935) may be either rare or non-existent in the Watsonville area of California.

The production of alates, however, could have an effect on the amount of movement. Since alatoid nymphs move very little, those factors which lead to a high percentage of alates would tend to reduce the total movement. This occurred in the experiment reported in table 10 when there was a marked reduction in movement following 96 hours in darkness.

Although a high percentage of alates may be produced in the laboratory under certain conditions, in the field very few alates were seen during 1956 and 1957. It does not seem likely that enough alates would be produced in the field to affect materially the amount of movement. This would mean that alate aphids are unimportant in either long-range or local movements in California. 


\section{FIELD STUDIES}

Materials and Methods. For field studies on the woolly apple aphid, an orchard of Yellow Newtown Pippin apples in the Watsonville area of California was selected. The trees in this orchard were approximately 25 years old and were moderately infested with the aphid. The soil type was clay loam, and the trees were on a gentle slope. This type of soil tends to crack when dry.

Although it would have been desirable to allow these trees to go entirely unsprayed, it was necessary to apply a spray for the control of rosy and green apple aphids. Demeton was very effective against these two aphids, but had been found to be relatively ineffective against the woolly apple aphid, so it was selected and sprayed on the trees during May of 1956 and 1957.

Since almost 100 per cent of the movement was carried out by the first instar nymphs soon after they were deposited, the most practical method of studying their movements was by trapping the aphids. To accomplish this, the bark scales were removed from a section of the trunk of a tree, and a wax-backed aluminum foil band was placed tightly around the tree in the smooth area. For most purposes, bands 2 inches wide were used, but in some areas on the limbs 1-inch bands were used. A strip of sticky polybutene material 1/2-inch wide was placed on the band. The aluminum foil provided a smooth surface and prevented the aphids from getting enough of a foothold to pull themselves out of the sticky band. The polybutene materials trapped the aphids at the two edges of the $1 / 2$-inch strip, thus separating those aphids which were moving up from those which were moving down. This method of trapping aphids was also described by Madsen and Hoyt (1957).

When the bands were removed from the trees, they were placed face down on a clear plastic material to facilitate handling. The numbers of aphids trapped moving up and down were then counted under a dissecting microscope.

Approximately 1 per cent of the aphids escaped being trapped by crawling under the bands. The aphids generally preferred to crawl over an obstacle rather than under it; this aided the effectiveness of the bands in trapping the aphids.

With the exception of one experiment, air temperatures were recorded with a hygrothermograph which was hung in the center of a tree with dense foliage.

Seasonal Movements of Aphids. In the study of seasonal movement, four of the demeton-treated trees were selected. It was felt that the treatment with demeton would have only a minor effect on the number of aphids moving, because it had been unsuccessful in the control of the woolly apple aphid, and because an examination of the limbs and trunks of the trees immediately prior to the time when the material was sprayed showed very few live woolly apple aphids present.

The trees were banded with 2-inch aluminum foil bands on the main trunk, approximately $1 \frac{1}{2}$ feet above the surface of the ground. The bands were 
changed at weekly intervals from May 7, 1956, through July 18, 1957. The bands were changed every 2 weeks when the movement reached a low level during late winter and early spring.

The number of aphids trapped by the bands was recorded as the number of aphids moving up the trunk and the number moving down the trunk. Those aphids moving down were deposited by females in colonies on the aerial portions of the tree. Most of the aphids moving up the tree were deposited on the roots and moved up to the trunk through cracks in the soil. A few may have represented aphids which dropped to the soil from the limbs and crawled back up the tree.

From these data the average daily movement for each week was calculated for the upward and for the downward movements. These averages are shown graphically in figure 4 for the upward movement and in figure 5 for the downward movement. It is felt that these figures also represent a fairly accurate index to the total populations of woolly apple aphids present on these trees.

Figure 6 shows the average maximum temperature per banding period from May 7, 1956, to June 6, 1957. These data were taken from the U. S. Department of Commerce publication, Climatological Data, California (1956 and 1957). The recording station is located at Watsonville, a distance of about five miles from the orchard.

By examining figure 4 it can be seen that the greatest number of aphids moving up took place during July and August. There is a great deal of variation in the total number of aphids moving on the different trees at different times of the year, but the curves of the average movement follow the same general trend on all the trees.

The soil around each tree may be responsible for the difference in the total number of aphids moving on the various trees. The type of soil and the extent of cracking in the soil affect the amount of infestation on the roots, according to Marcovitch (1934), who stated that sandy soils inhibit infestation by the aphid while heavy soils which crack favor it. Differences in the amount of cracking of the soil seemed to occur, but some cracking was evident around all of the trees.

A second point to be considered in figure 4 is that the number moving does not increase or decrease at a steady rate. In each peak of movement several sub-peaks occur. Just what causes an increase in movement one week followed by a decrease the next week in the more or less uniform environment of the soil is difficult to say. However, most of the sub-peaks on the four different trees occurred at the same time, suggesting a common cause on all trees.

One factor of the environment which may have some effect on the number of aphids moving from week to week is rainfall. When a sufficient amount of rain fell to seal the cracks in the soil, aphids were prevented from coming up through the soil and up the tree. Rain also might wash aphids off of the tree trunk. A third possible effect of rain would be the cooling of the soil. At the top of figure 4 is a record of the total rainfall, in inches, during each banding period from May 7, 1956, to June 30, 1957. These data were also taken from the U. S. Department of Commerce publication, Climatological Data, California (1956 and 1957). These records were kept at the Watsonville station. 
284

Hilgardia

[Vol. 30, No. 10
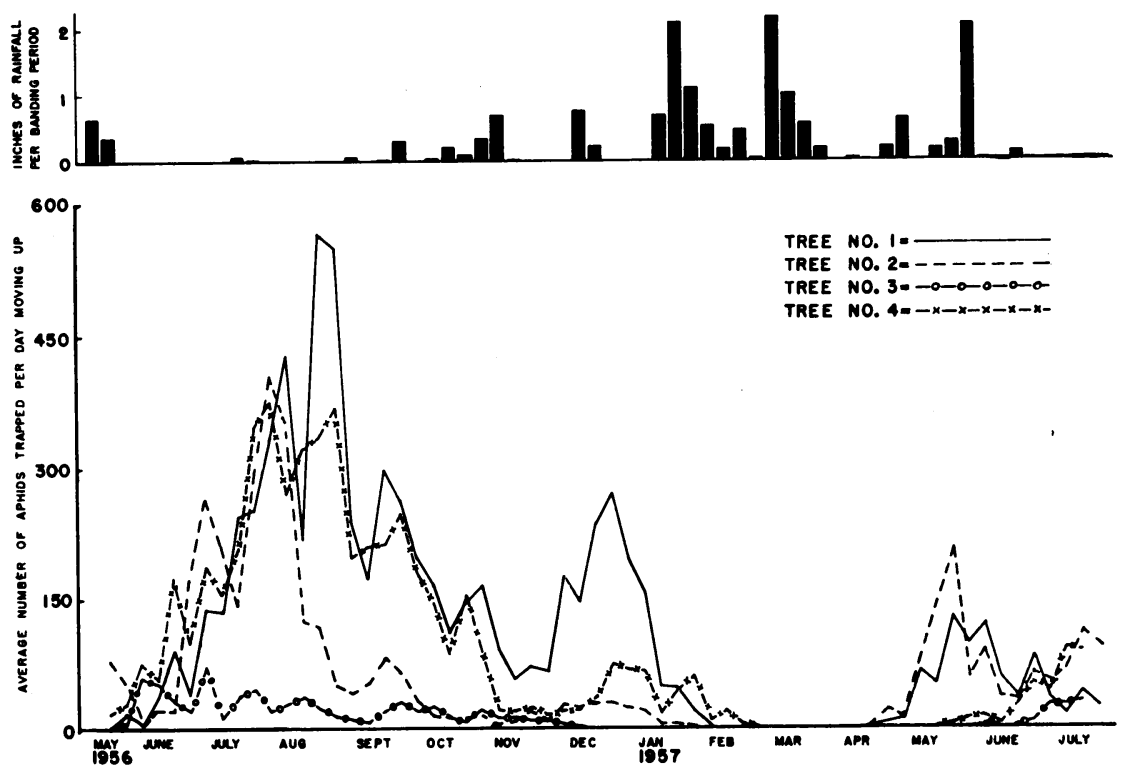

Fig. 4. Average number of aphids trapped moving upward per day during the weekly banding periods of 1956 and 1957, and total rainfall, in inches.

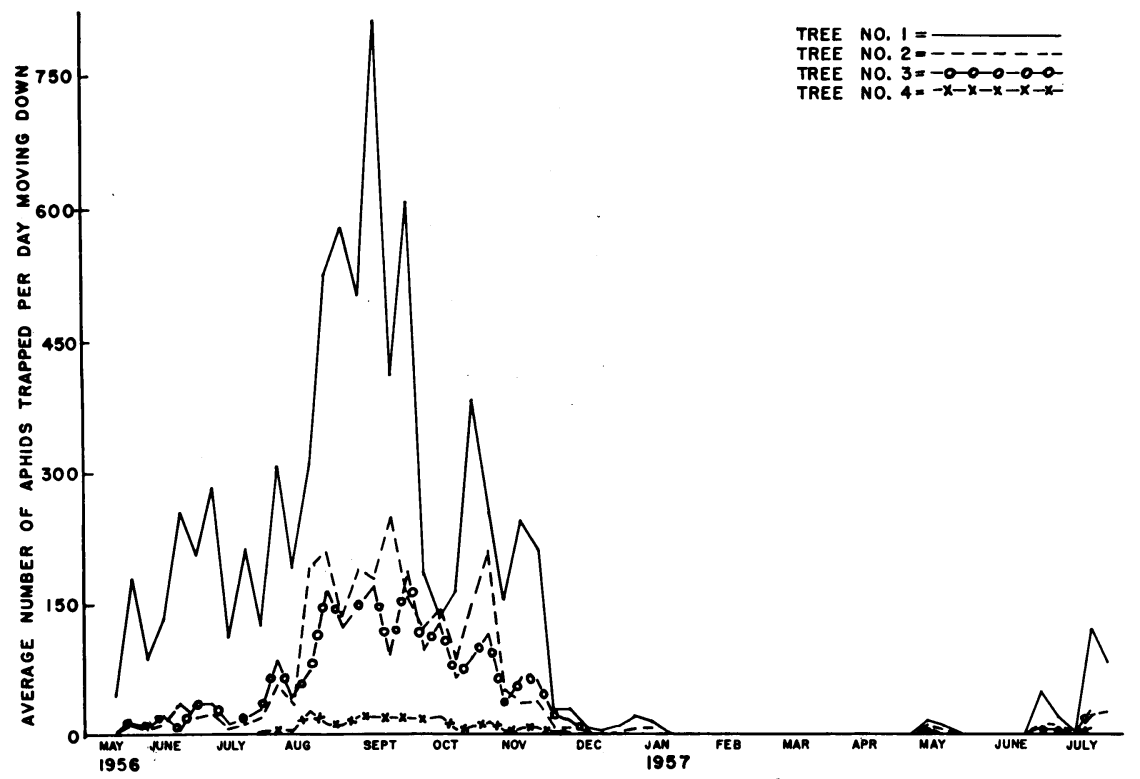

Fig. 5. Average number of aphids trapped moving downward per day during the weekly banding periods of 1956 and 1957 . 
On several occasions, a heavy rainfall showed a correlation with a decline in the number of aphids moving. Although rainfall can explain many of the week-to-week decreases in the amount of movement, there are still many cases of decline unexplained by this factor.

The rapid decline in the amount of upward movement which took place in early January of 1957 was not all due to heavy rainfall. During this period the temperatures dropped to a very low level. The average maximum temperatures remained below $60^{\circ} \mathrm{F}$ for 5 weeks and below $63^{\circ} \mathrm{F}$ until the last

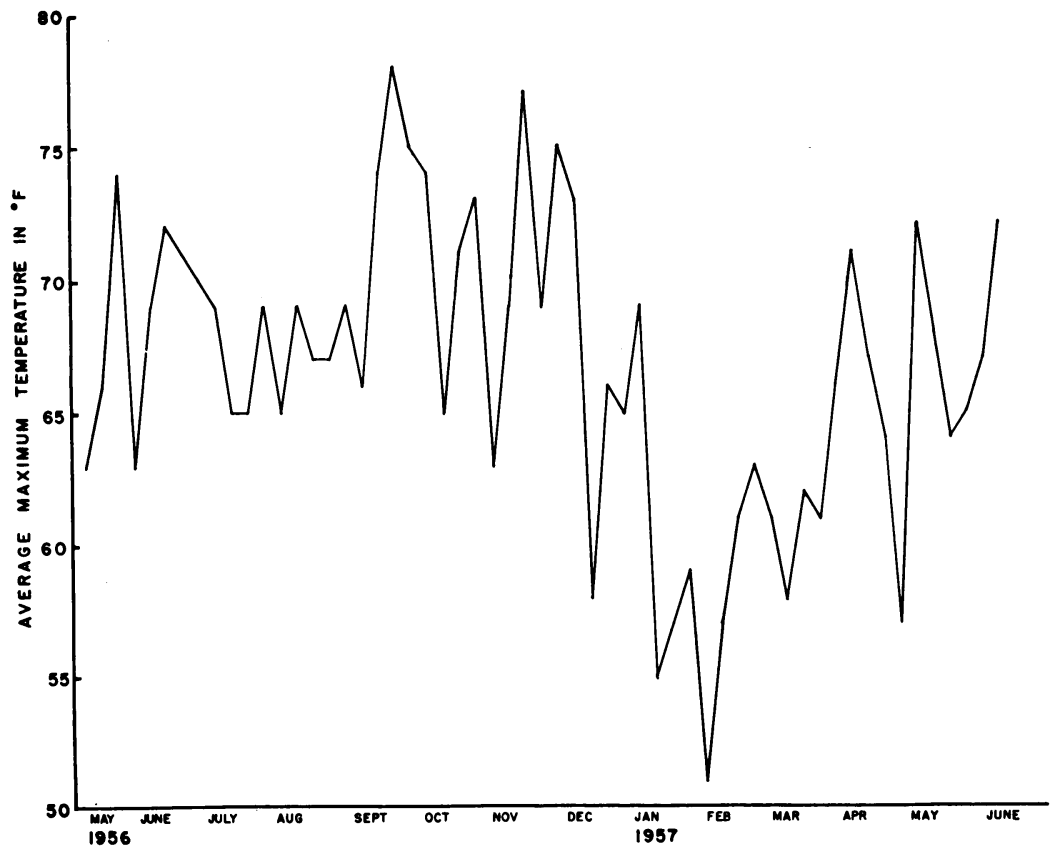

Fig. 6. Average maximum temperature per weekly banding period.

week in March (figure 6). According to Schoene and Underhill (1935), the crawlers are only slightly active at $60^{\circ} \mathrm{F}$ or below. In addition to the decreased activity by the crawlers, temperatures this low would not be favorable to the deposition of large numbers of aphids.

On April 6, 1957, the cover crop present in the orchard was removed. Just how much effect this had on the number of nymphs moving is unknown, but a warming of the soil follows removal of the cover crop in the spring. From this time on, the number of aphids moving increased.

It is also clear that the upward movement during June and July of 1957 was much less than during the same months of 1956. The one outstanding factor which may have led to this is the large amount of precipitation which occurred in May of 1957.

By examining figure 5, several things can be seen with regard to the average daily movement down. It should be remembered that these aphids were deposited by females in colonies which were on the limbs where they were exposed to a more intense action by parasites and predators, and to more 
extreme weather conditions than those colonies on the roots. More violent fluctuations would be expected to occur in the number of aphids moving down than in the number moving up. By examining the curves in figure 5, greater fluctuations in movement from week to week are seen to occur than are noted in figure 4 . This leads to a curve with many peaks and deep valleys between them.

By comparing figures 5 and 6 , several of these peaks of aphid movement are seen to correspond to the peaks of temperature. Since the number of aphids produced depends on the temperature, it would be expected that changes in temperature from week to week would affect the number of aphids moving.

In addition, it is noteworthy that the curves of the average number of aphids moving on the 4 different trees follow a more uniform pattern in figure 5 than in figure 4 . The amount of movement on each of the 4 trees was at its peak from the middle of August until the middle of September. A second peak of movement occurred in late October. Following a rapid decline in the amount of movement during November, downward movement was practically nonexistent until late June of 1957.

The number of aphids moving depended on the number of aphids being produced. The number of aphids produced depended mainly on the number of females present and the temperature. Garman and Townsend (1952) and Bodenheimer (1947) found that the optimum for a population increase by this insect was in the range of $60^{\circ}$ to $70^{\circ} \mathrm{F}$, and Marcovitch (1934) found that the optimum was $68^{\circ} \mathrm{F}$. Temperatures in this favorable range occurred often during June, July, and August.

During January, February, and March of 1957, large numbers of the woolly apple aphid parasite, Aphelinus mali Haldeman, were present in the orchard. The adults were emerging from previously parasitized aphids in the limb colonies and were searching for new hosts. These parasites played a major role in the reduction in downward movement which occurred in late November of 1956, by reducing the population of females present. By April of 1957, a large number of parasitized aphids could be found on the limbs, but practically no live aphids were present.

Owing to the low number of live aphids present on the limbs and the very small amount of upward movement during the spring of 1957, the formation of new colonies in the aerial portions of the tree was a slow process. This resulted in a very small population of aphids and very little downward movement until the beginning of July, 1957.

A comparison of figures 4 and 5 shows that there was a continuous movement of aphids both up and down during the summer and fall. This disagrees with the findings of Theobald (1920), who stated that there is an upward movement in the early summer and a downward movement in the fall in England.

A second fact seen by this comparison is that a large amount of upward and downward movement can occur on the same tree. However, a large number of aphids moving upward did not necessarily result in a large number moving downward. Tree 4 had a large number of aphids moving upward, but very little downward movement occurred at any time during the observations. Conversely, a large number of aphids moving downward did not 
necessarily result in a great amount of upward movement. Tree 3 is an example of this where very few aphids moved upward, but a large number moved downward.

Daily Movement of Aphids. An experiment similar to that on seasonal movement of aphids was employed to determine the relative numbers of aphids moving at different times of the day. Four trees were banded in the same manner as in the previous experiment. In this case, the bands were removed and replaced every 2 hours for a 24 -hour period. This was repeated on several days during the late spring and early summer of 1956 . Since the amount of movement on the different trees and days showed a similar pattern, the results from only 2 days are illustrated.

During the summer in the Watsonville area there are many days with high morning fog which clears later in the day. Since this type of weather is so common, one of the daily movement samples is from a day with these conditions. The other sample is from a day on which there was no fog or overcast during the experiment. Temperatures were recorded with a hygrothermograph which was placed in a tree with heavy foliage.

Figure 7 shows the daily movement of aphids on a day with a foggy morning, and clear afternoon and evening. The curve of the movement downward appears to follow the curve of temperature except for a slight lag in the morning hours. The curve of the upward movement also seems to follow the curve of temperature. In this case, however, the number of aphids moving upward starts to increase at the same time as the temperatures start to rise. Also, the peak of the upward movement is sharp while that for the downward movement is more extended in length.

Figure 8 shows the daily movement of aphids on a day when there was no overcast. In this case, the curve of the downward movement is very similar to that on a foggy day. The curve again follows the curve of temperature with a lag in the morning hours. The peak is again more extended in length than the peak of the upward movement. The curve of the upward movement does not follow the temperature curve for the entire 24 hours; there is a rapid increase in the number of aphids moving in the early morning hours, reaching a peak at approximately 10:00 a.m. It is at this point that the departure from the temperature curve shown takes place. The amount of movement decreases during the early afternoon, but climbs to a second, higher peak between 4:00 and 6:00 p.m. From this point, the curve follows the temperature curve until 10:00 a.m. the next morning.

The temperature curve shown in figure 8 is from temperatures recorded in a shaded area. The curve is representative of the temperatures affecting the aphids in the aerial portions of the tree or on a foggy day, but it is not representative of the temperatures at the soil surface or at the base of the tree during the morning hours when direct sunlight fell on these areas. It is suggested, therefore, that the early peak of upward movement on a sunny day was due to a rapid warming of the soil surface by the sun. This surface was shaded during the early afternoon hours, and the amount of movement showed a consequent decrease.

It should be pointed out that some movement occurred in the early morning hours, although it was at a very low level in both directions. During the nights on which the movement was measured, the temperatures were below 


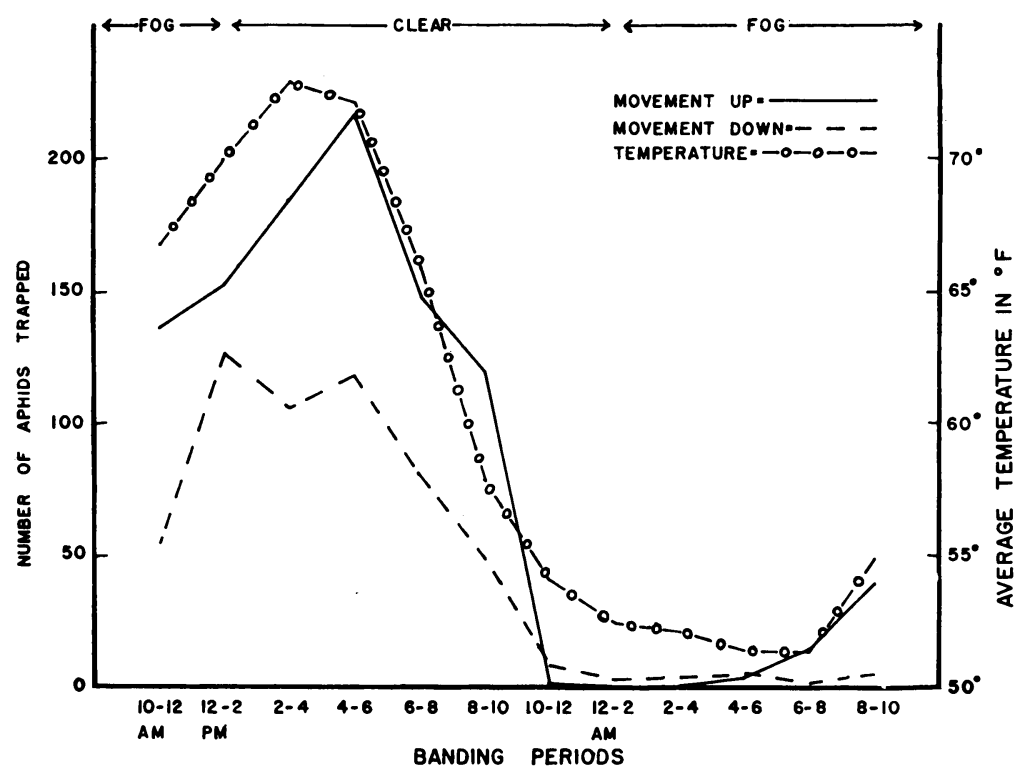

Fig. 7. Average temperature, and number of aphids trapped per 2-hour period, on a day with morning fog.

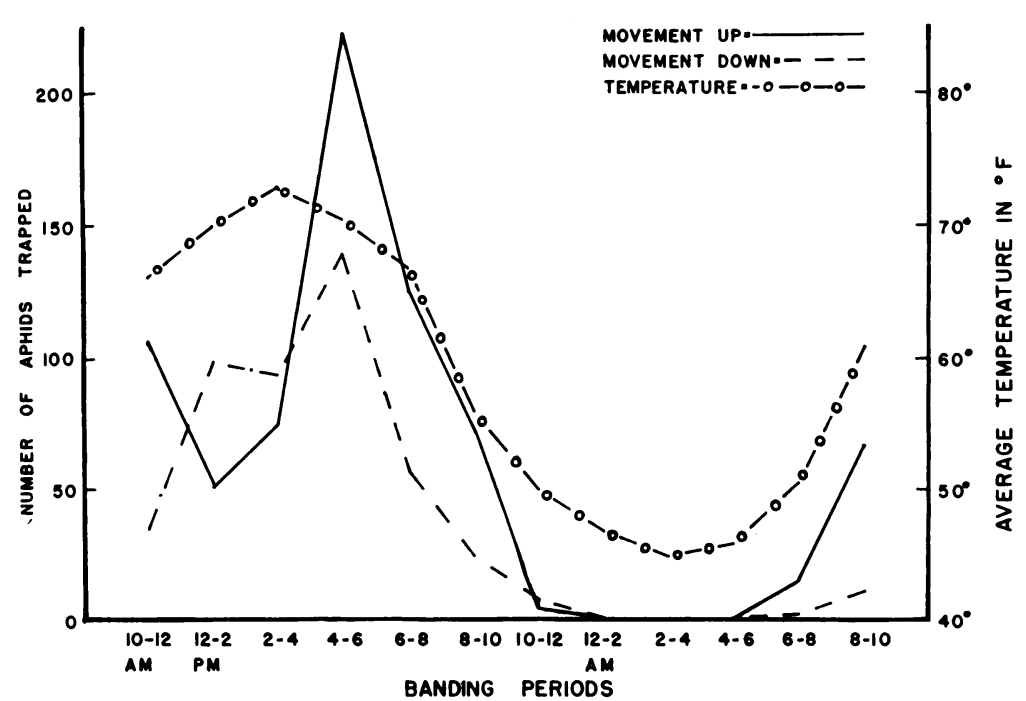

Fig. 8. Average temperature, and number of aphids trapped per 2-hour period, on a clear day. 
$50^{\circ} \mathrm{F}$. The laboratory studies showed that neither temperatures this low nor darkness were conducive to movement.

Temperature Gradients and Movement in the Field. The striking effect of temperature gradients on the movement of aphids in the laboratory stimulated an interest in the importance of these gradients in the field.

Trees again were banded with 2-inch foil bands for 2-hour periods, and the number of aphids moving up and down was recorded. During the hours when the sun shone on the tree trunks, the number of aphids trapped on the sunny and shady sides of the tree were recorded separately.

The recording potentiometer with thermocouples was used to measure and to record the temperatures at various points on the tree. A tree more or less representative of the trees in the orchard was chosen for the measurements. Thermocouples were placed $1 / 2$ inch from the tree at the following points: 1 inch in the soil ; and 1 inch, 1 foot, 2 feet, 4 feet, and 8 feet above the surface of the ground. They were placed at these levels on both the southeast and northwest sides of the tree.

The temperatures were averaged for 2-hour periods from 6:00 a.m. through 8:00 p.m. for each point. Since the temperature averages on the three different days were similar, the average of the 3 days at each point was calculated. These temperature gradients, excepting the point 1 inch in the soil, are shown in figures 9 and 10 .

On the southeast side of the tree from 1 inch to 8 feet above the soil, temperature differences of $6^{\circ} \mathrm{F}$ or more occurred only between 6:00 to 8:00 a.m. and 8:00 to 10:00 a.m. (see figure 9). Between 10:00 a.m. and 8:00 p.m., the temperature differences over this distance did not exceed $2^{\circ} \mathrm{F}$. On the northwest side of the tree between these same points, a temperature difference of $51 / 2{ }^{\circ} \mathrm{F}$ occurred between 6:00 and 8:00 p.m. (see figure 10). Between 6:00 a.m. and 6:00 p.m., the differences did not exceed 21/2 ${ }^{\circ} \mathrm{F}$.

Between 8:00 a.m. and 6:00 p.m. the temperature was $5^{\circ}$ to $10^{\circ} \mathrm{F}$ lower 1 inch in the soil than 1 inch above it. Between 6:00 and 8:00 a.m. or 6:00 and 8:00 p.m. the temperature 1 inch in the soil slightly exceeded or was nearly equal to the temperature 1 inch above the soil.

Those temperature gradients which are significant in their extent are a result of direct sunlight falling on the exposed surfaces. A comparison of figures 9 and 10 shows that at these times the temperature gradients from the sunny to the shady side of the tree trunk were more extensive than those from 1 inch above the surface of the ground up the trunk. If the aphids were reacting to differences in temperatures, they would be expected to move around the tree trunk from the sunny to the shady side or vice versa. The band counts during these periods showed no significant differences between the number of aphids trapped on the shady and on the sunny sides of the tree.

In the laboratory, wider temperature gradients over shorter distances affected the direction of aphid movements. In the field, however, the differences existing in the temperatures at the different points were not great enough to affect the direction of movement of the aphids during most of the day. Although temperature may affect the amount of movement in the field, other factors are probably more important in determining the direction of movement, once the aphids are above the surface of the ground. It is pos- 


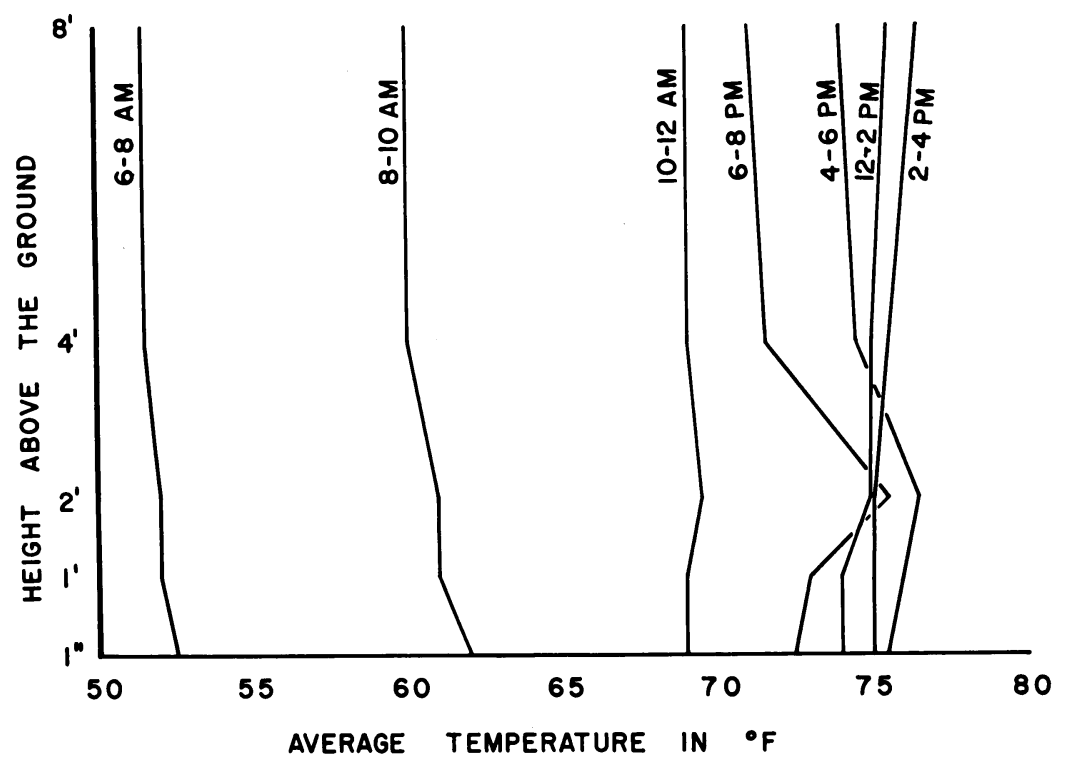

Fig. 9. Average temperatures for 2-hour periods at various distances above the ground on the southeast side of a tree.

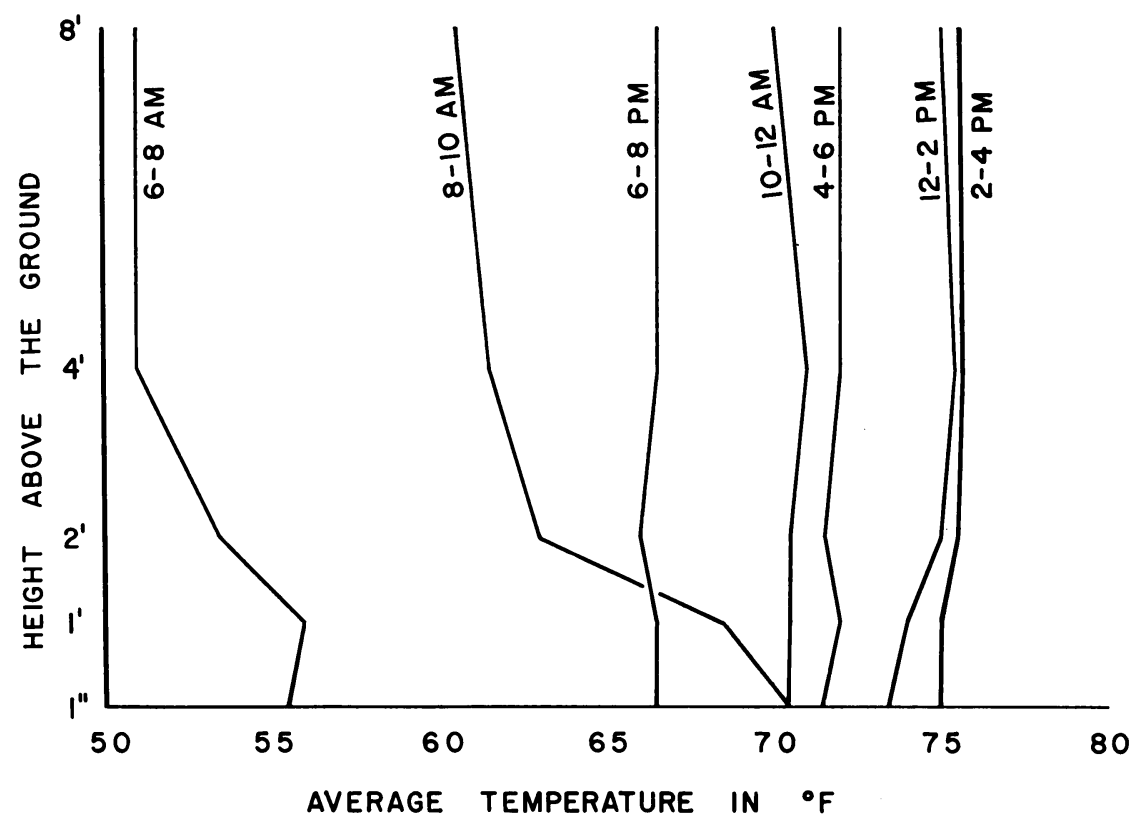

Fig. 10. Average temperatures for 2-hour periods at various distances above the ground on the northwest side of a tree. 
sible that temperature gradients are important in directing movement from the roots to the soil surface.

The Number of Aphids Moving Up or Down Out of Individual Colonies. This experiment was designed to determine whether or not the movement out of individual aerial colonies is random. If the direction of movement taken by the newly deposited nymphs is purely random, then 50 per cent would be expected to go up and 50 per cent would be expected to go down.

To determine this, 1-inch foil bands with sticky material were placed immediately above and below the colonies to be checked. These bands remained on the limbs from 8:00 a. m. until 4:00 p.m. each day, and the test was run for 4 days in 1957. Large or average size colonies were selected so

TABLE 11

MOVEMENT OF FIRST INSTAR WOOLLY APPLE APHIDS FROM INDIVIDUAL COLONIES

\begin{tabular}{|c|c|c|c|c|c|c|c|c|c|c|}
\hline \multirow{3}{*}{ Colony No. } & \multicolumn{10}{|c|}{ Number of aphids trapped per 8 hours } \\
\hline & \multicolumn{2}{|c|}{ July 29} & \multicolumn{2}{|c|}{ July 30} & \multicolumn{2}{|c|}{ July 31} & \multicolumn{2}{|c|}{ August 1} & \multicolumn{2}{|c|}{ Total } \\
\hline & $\mathrm{Up}^{*}$ & Down $\dagger$ & $\mathrm{Up}$ & Down & $\mathrm{Up}$ & Down & $\mathrm{Up}$ & Down & Up & Down \\
\hline 1. & 29 & 49 & 45 & 61 & 26 & 65 & 33 & 57 & 133 & 232 \\
\hline 2. & 6 & 38 & 12 & 31 & 15 & 28 & 10 & 24 & 43 & 121 \\
\hline 3. & .. & .. & .. & .. & 93 & 212 & 77 & 126 & 170 & 338 \\
\hline $4 \ldots$ & 6 & 30 & 14 & 52 & 12 & 56 & 3 & 45 & 35 & 183 \\
\hline $5 \ldots$ & 17 & 27 & 24 & 52 & 21 & 30 & 14 & 33 & 76 & 142 \\
\hline $6 \ldots$ & 14 & 15 & 25 & 34 & 34 & 40 & 81 & 27 & 154 & 116 \\
\hline $7 \ldots \ldots$ & 31 & 35 & 39 & 32 & 36 & 31 & 20 & 41 & 126 & 139 \\
\hline $8 \ldots \ldots$ & 44 & 77 & 56 & 81 & 48 & 77 & 25 & 74 & 173 & 309 \\
\hline $9 \ldots \ldots \ldots \ldots$ & 11 & 38 & 21 & 31 & 3 & 36 & 5 & 21 & 40 & 126 \\
\hline $10 \ldots \ldots \ldots \ldots$ & 37 & 24 & 39 & 9 & 23 & 24 & 19 & 23 & 118 & 80 \\
\hline Total......... & 255 & 333 & 275 & 383 & 218 & 387 & 210 & 345 & 1068 & 1786 \\
\hline Percentage. . & 43 & 57 & 42 & 58 & 36 & 64 & 37 & 63 & 37.4 & 62.6 \\
\hline
\end{tabular}

* Movement toward the tip of the limb.

$\dagger$ Movement toward the trunk of the tree.

that the amount of movement would be significant. The colonies were also selected for their location or for the position of the limb on which they occurred with respect to the ground, that is, whether the limb ran parallel to the ground, obliquely up away from the ground, obliquely down toward the ground, or vertically away from the ground. In all cases, aphids moving toward the trunk of the tree were recorded as moving down and those moving toward the tips of the limbs as moving up. The numbers of aphids moving up and down from the different colonies are listed in table 11 .

From this table it is clear that, with only a few exceptions, the majority of the aphids move down out of individual colonies. The position of the limb seemed to have little effect on the direction of movement. However, the location of colony 10 may have had some effect on the high percentage of upward movement, since it was the only colony exposed to direct sunlight during the tests.

In 1956, several single colonies were banded in this same manner for 1week intervals. Out of 10 colonies, in only one case did the upward move- 
ment decisively exceed the downward. In one other colony, the amount of movement in both directions was approximately equal. Of the total movement from the 10 colonies, 59 per cent of the aphids moved downward.

This suggests that a non-random movement out of these colonies occurred. This would mean that, immediately upon being deposited, most of the young nymphs reacted to a stimulus to move in a particular direction, which in this case was downward. Since some of these colonies were on limbs which were parallel to the ground, a positive geotropism could not have been the stimulus in all cases. Light may have been a factor in directing the movements, since a slight gradient exists from the tips of the limbs to the center of the tree.

TABLE 12

MOVEMENT OF FIRST INSTAR WOOLLY APPLE APHID NYMPHS AT LIMB JUNCTIONS

\begin{tabular}{|c|c|c|c|}
\hline \multirow{2}{*}{ Date } & \multirow{2}{*}{ Limb no. } & \multicolumn{2}{|c|}{ Number of aphids trapped } \\
\hline & & $\begin{array}{c}\text { Continuing } \\
\text { down }\end{array}$ & $\begin{array}{l}\text { Going up the } \\
\text { other limb }\end{array}$ \\
\hline July 29 & $\begin{array}{l}1 \\
2 \\
3 \\
4\end{array}$ & $\begin{array}{r}29 \\
88 \\
92 \\
221\end{array}$ & $\begin{array}{r}7 \\
14 \\
8 \\
19\end{array}$ \\
\hline July 30 . & $\begin{array}{l}1 \\
2 \\
3 \\
4\end{array}$ & $\begin{array}{r}40 \\
104 \\
122 \\
237\end{array}$ & $\begin{array}{r}6 \\
18 \\
16 \\
17\end{array}$ \\
\hline July 31 & $\begin{array}{l}1 \\
2 \\
3 \\
4\end{array}$ & $\begin{array}{r}31 \\
152 \\
120 \\
214\end{array}$ & $\begin{array}{r}4 \\
16 \\
6 \\
18\end{array}$ \\
\hline August 1 & $\begin{array}{l}1 \\
2 \\
3 \\
4\end{array}$ & $\begin{array}{l}18 \\
81 \\
49 \\
82\end{array}$ & $\begin{array}{r}5 \\
17 \\
5 \\
11\end{array}$ \\
\hline $\begin{array}{l}\text { Total........... } \\
\text { Percentage.... }\end{array}$ & $\begin{array}{l}. . \\
. .\end{array}$ & $\begin{array}{r}1680 \\
90\end{array}$ & $\begin{array}{r}187 \\
10\end{array}$ \\
\hline
\end{tabular}

Change of Direction of Movement. This experiment was designed to determine if aphids which were moving down one limb of a tree would reverse their direction and move up upon encountering a junction with another limb.

Trees were banded on one limb about 6 inches above a junction. Two bands were placed about 6 and 9 inches below this union of the two limbs. Two separate bands were used to insure that aphids coming up from the roots would not interfere with the test. All colonies in the immediate area of the bands were destroyed. The only aphids which could be trapped moving up on the top band were those which had come down one limb, reversed their direction, and gone up the other limb.

The number of aphids moving down only, and the number of aphids which reversed their direction of movement are listed in table 12 , in which it is shown that 90 per cent of the aphids had continued moving in their original 
direction, and 10 per cent had reversed their direction and had gone up upon encountering the limb union.

Movement Up in the Light and in the Dark. The purpose of this experiment was to determine the effect of light on the upward movement of aphids. Two trees were banded with sticky bands for 2 consecutive days and the number of aphids moving on these trees was recorded. At 6:00 p.m. on the second day, a frame was built around the base of one of the trees. The frame was covered with a light-proof shelter, so that the bands could be changed easily but no light could fall on the base of the tree or on the surrounding

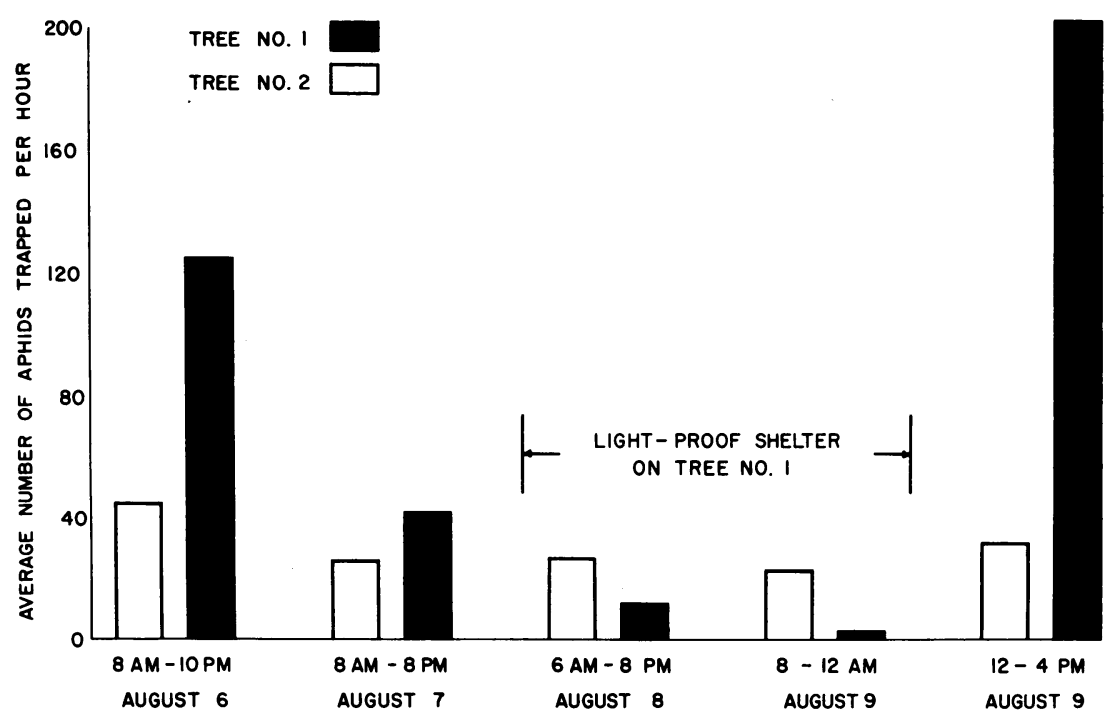

Fig. 11. Average number of aphids trapped moving upward per hour, in the light and in the dark.

soil. The light-proof shelter remained on this tree until noon of the fourth day. The other tree remained in normal daylight during the third and fourth days. The results of this experiment are shown in figure 11.

According to the figure, there was a considerably higher number of aphids moving on tree 1 than on tree 2 on the first and second days. When the lightproof shelter was placed around tree 1, the movement of aphids was reduced to a very low level, considerably below that on tree 2 . When the shelter was removed, the amount of movement increased rapidly to a very high level in the next 4 hours. Tree 2, unsheltered at all times, showed similar amounts of movement on all four days. The number of aphids moving on tree 2 did not rise to a high level on the fourth day.

Since temperatures were not measured in the shelter, this experiment was repeated in 1957. One tree was banded from 7:00 to 11:00 a.m. on each of four days. On the second and fourth days, the light-proof shelter was placed on the tree. The temperatures inside of the shelter differed only slightly from those outside. In this test, 216 aphids were trapped during a total of 8 hours in the light, while only 22 were trapped during the 8 hours in the dark. 
This shows the importance of light in the upward movement of aphids and confirms the experiments conducted in the laboratory.

Infestation of Apple Cores by the Woolly Apple Aphid. To determine the relative number of apple cores infested with aphids at various times during the summer, 100 apples were collected at random from the test trees used in the previous experiments. The apples were cut open and examined for the presence of woolly aphids.

On the first two dates on which the fruit was examined, June 13 and July 4, 1956, there were no infested apple cores, even though an opening from the calyx to the core existed in many of the fruits. From this time on, the percentage of fruit infested by the aphids showed a steady increase: on July 19, 3 per cent; on August 9, 6 per cent ; on August 30, 12 per cent ; and at harvest on September 27, 15 per cent.

This infestation took place at a time when a large number of aphids were moving on the trees (figures 4 and 5). The infestation was probably due to an accidental entry into the calyx by one of the extremely large number of aphids searching for colony sites, rather than a direct attraction to the core of the fruit. If the infestation were brought about by some attraction to the fruit, a much higher percentage of infested cores would be expected, owing to the high aphid population present.

\section{DISCUSSION}

Throughout the experiments the apterous forms important in the local movements are the first instar nymphs. The older apterous forms remain more or less sessile, unless they were disturbed by extreme environmental conditions. The alates were found to be unimportant in either local or long range movements, unless extreme conditions caused a high percentage of alates to be deposited. This would, in effect, reduce the populations of apterous nymphs on the trees and hence decrease the total movement.

Apterous nymphs, upon being deposited, established near the parent female, or moved up or down the tree in search of colonies of aphids or colony sites. The aphids were capable of searching for 2 or more days before they settled down to feed. They seemed to bypass obstructions and possible colony sites until their behavior changed suddenly. At this time they examined every crack and scar in their path as a possible settling point.

In the field, of those aphids deposited in colonies on the aerial portions of the tree, approximately 60 per cent crawled down and 40 per cent crawled up the limbs. Of the 40 per cent crawling up, some joined colonies higher up on the limbs, some formed new colonies, some were blown from the branch tips, and some reversed their direction and started down. Of the 60 per cent that crawled down, approximately 10 per cent reversed direction and crawled back up other limbs. If the population was at a low level, most of the aphids that did not reverse their direction crawled down the trunk, some entering cracks in the soil and others crawling over the soil surface. If the population was large, numerous aphids dropped from the limbs and the trunk to the soil surface, while many other aphids crawled down the trunk and into or onto the soil. The exact fate of those aphids crawling over the soil surface is unknown, but it is assumed that a high rate of mortality 
occurred, since no attraction back to the tree was evident. When populations of aphids were high, some of the aphids searching for colony sites entered the open calyx of some apples and established colonies.

The colonies on the roots, in general, were smaller in size than those on the aerial portions of the tree, but some large colonies existed just below the surface of the ground on the main roots. Whether or not any movement down from these root colonies occurred was not determined, but many aphids moved up through cracks in the soil to the surface. Probably only a very small percentage of those aphids that reached the soil surface survived. These found the trunk of the tree and crawled up to the limbs to establish new colonies or to join old colonies. In some cases, however, the fate of the aphids moving up is unknown, since no colony formation was observed in the aerial portion of some trees.

On a seasonal basis, the greatest number of aphids moved during the summer months, and the least number moved during late winter and early spring. On a day-to-day basis, the greatest amount of movement occurred in the late afternoon when the temperature was highest. A large amount of upward movement occurred in the morning of a sunny day, but very little movement occurred during the hours of darkness.

Most of the experiments demonstrated that the aphids rarely exhibit a zero or 100 per cent reaction to any one factor. In the laboratory, several factors were found to influence the direction of aphid movement. In the field, the factors controlling amount of movement were more discernible than those controlling direction.

The effects of temperature on the movement of this aphid were important both in the laboratory and in the field. In the laboratory, temperature gradients were found to influence the direction of movement. The majority of the aphids moved to low temperatures when the range of temperature was high, but the reverse was true when the range of temperature was low. When the midpoint of the range was about $65^{\circ} \mathrm{F}$, approximately 50 per cent of the aphids would move in either direction. If the extremes of the temperature range were no more than a few degrees apart, there was little effect on aphid movement. Though these gradients were important in the laboratory, their importance as a stimulus to movements in the field is questionable, because the differences in temperatures were smaller over longer distances.

The second important effect of temperature was that it influenced the number of aphids produced. As the season advanced and temperatures reached a favorable range, higher numbers of aphids were produced. These established colonies and, at favorable temperatures, produced more aphids which moved over the tree. This cycle continued so long as favorable temperatures existed and other factors did not interfere.

Third, if temperatures were too low, no movement occurred, even if aphids were present. The number of aphids moving as well as the speed of crawling of aphids increased as the temperature rose.

Since the curves of the daily movement and of the daily temperatures were similar, the temperature was probably acting in both of the latter ways on the daily movements. As temperatures rose, those aphids present became more active and more nymphs were deposited.

Another extremely important factor of the physical environment which 
influenced aphid movements was light. In the laboratory, the majority of the aphids were negatively phototropic, the percentage increasing as the temperature rose. If the light source was combined with the low temperature of a temperature gradient, the repellent effect of the light was reduced. If aphids moving up in the field were collected, upward movement was continued by 87 per cent of them. The predominant factor that stimulated upward movement was light.

A second effect of light was on the amount of movement. If the light was blocked off from a tree, the movement was reduced to a low level, even though the temperature remained the same. This effect may have been due partly to the importance of light in directing the movement. If the light was removed, the aphids then wandered at random. This effect on the amount of movement was also evidenced by the fact that very little movement occurred at night. Light also brought about a warming of the soil in the morning when direct sunlight fell on the surface of the ground. This caused a peak of movement upward at about 10:00 a.m. The warming effect was also shown by a removal of the cover crop.

Aphids collected in the laboratory showed a strong positive geotropism, since 80 per cent moved down in the dark. These aphids were collected from crowded colonies shortly after they were deposited. Since 60 per cent of the aphids deposited in limb colonies in the field moved downward, it seems reasonable to assume that gravity played a part in directing their movements. It must be remembered, however, that greater numbers of aphids moved away from the limb tips, even when the limbs were parallel to the ground and gravity was not a factor.

Wind affected the direction of movement on smooth surfaces in the laboratory, but these conditions do not occur in the field on the surface of the ground. In the orchard, the wind direction and velocity were variable, and no sustained effect would occur. Another effect of wind would be simply that of blowing aphids from the tree to the soil or, in high winds, to other trees.

In the field studies, rain was found to affect the amount of movement in several ways. Heavy rains eaused a temporary sealing of the cracks in the soil through which the aphids moved. The second effect was the reduction of temperature brought about by moisture in the soil. In addition, heavy rains washed or knocked aphids from the trees. All of these actions would tend to reduce the numbers of aphids moving on the trees.

Parasites and predators also reduced the number of aphids moving down the trees by reducing the number of mature females. In fact, during the first year of study the action of parasites was one of the most outstanding factors in the reduction of the aphid population present on the aerial portions of the trees.

The dispersal behavior of the woolly apple aphid is not purely a random movement, but is a response to definite stimuli. From these studies it can be concluded that many factors can influence both the direction and the amount of movement, and no one factor is dominant at all times. 


\section{SUMMARY}

The woolly apple aphid, Eriosoma lanigerum (Hausmann), is a pest of major importance wherever apples are grown. Its presence in the core of fruit, and continuous movements by the first instar nymphs, prompted a study of the factors affecting these movements.

Laboratory studies were conducted at Berkeley, California, with aphids reared on seedling trees. Aphids were collected from these trees, to study the effect of temperature gradients on movement. First instar apterous nymphs are the forms important in the dispersion. Older apterous forms are more or less sessile, and, in California, alates apparently produce sterile sexual forms. The majority of the aphids were repelled by temperatures above $70^{\circ} \mathrm{F}$ or below $60^{\circ} \mathrm{F}$; the majority of the aphids were attracted to temperatures between $60^{\circ} \mathrm{F}$ and $70^{\circ} \mathrm{F}$, and in this range their movements were random. Temperatures below $50^{\circ} \mathrm{F}$ inhibited movement. Although temperature gradients were important in the laboratory, the gradients occurring above the ground in the field were rarely great enough over a short distance to affect the direction of movement. Gradients around the tree trunk were greater than those up the trunk, but no correlation between aphid movement and these gradients was found.

The greatest percentage of the aphids showed a negative phototropism in the laboratory, the percentage increasing as the temperature was raised. When a light source was combined with a temperature gradient, high temperatures and light were highly repellent to the aphids. Low temperatures of a gradient and a light source together reduced the attractant effect of temperatures between $60^{\circ} \mathrm{F}$ and $70^{\circ} \mathrm{F}$ and also reduced the repellent effect of a light source.

A large percentage of the laboratory-collected aphids showed a positive geotropism, but aphids collected in the field moving up on a tree trunk showed no obvious geotropic response. The latter aphids appeared to respond to light as a stimulus.

Air movement over a smooth surface in the laboratory caused the majority of the aphids to orient themselves with or against the flow of air. In the field, the surface of the ground was not smooth and wind direction was variable. As a result, the orientation of the aphids did not appear to be affected by air movements.

Studies of seasonal movements showed that the number of aphids moving up the tree increased during May and June, reached a high level during July and August, and declined during September, October, and November. A second peak of upward movement occurred during December, followed by a rapid decline in January. Activity then remained at a low level until midApril. The number of aphids moving down showed a rapid increase during May, June, and July, reaching a high peak during August and September. A rapid decline in movement occurred during October and November, and the number of aphids moving down remained at a low level until the following June.

The amount of rainfall affected the number of aphids moving up, with heavy rains causing a reduction in movement. Light also affected the amount of upward movement, since, in its absence, very few aphids moved up out of 
the soil. Low temperatures and parasites were the major factors that brought about a reduction in the amount of downward movement. Low temperatures not only decreased the number of aphids deposited, but also decreased the rate of dispersal.

On a day-to-day basis, the curve of the amount of movement followed the curve of temperature, except for a morning peak of upward movement when the sun shone on the base of the tree. The greatest amount of movement occurred in the late afternoon, and very little occurred during the hours of darkness.

Sticky bands were placed immediately above and below single colonies to determine the direction of movement. Sixty per cent of the aphids moving from these colonies went down. Ten per cent of the aphids moving down a limb were found to reverse their direction and go up upon encountering another limb.

Infestation of the apple cores by the aphids occurred during the late summer when the number of aphids moving was very high, and was probably due to accidental entry into the core.

\section{ACKNOWLEDGMENTS}

The writers wish to express their sincere gratitude to Ray F. Smith and E. M. Stafford, Department of Entomology and Parasitology, University of California, Berkeley-Davis, and to M. M. Barnes, Department of Entomology, Citrus Experiment Station, University of California, Riverside, for their helpful criticism during the investigation and in the preparation of the manuscript.

Further appreciation is extended to E. O. Essig, Professor Emeritus, for identification of the aphids, and to Ray Travers of Watsonville, California, for the use of his orchard and equipment. Microenvironmental conditions were determined with the assistance of personnel associated with the National Institute of Health, Public Health Service Grant E-885.

\section{LITERATURE CITED}

BAKER, A.C.

1915. The woolly apple aphis. U. S. Dept. Agr. Off. Sec. Rept. 101: 1-55.

BODEN HEIMER, F. S.

1947. Studies on the physical ecology of the woolly apple aphis (Eriosoma lanigerum) and its parasite, Aphelinus mali, in Palestine. Rehoboth Agr. Exp. Sta. Bul. 43: $1-20$.

BritTAin, W. H.

1936. Sucking insects of the apple. Nova Scotia Fruit Growers Assoc. Rept. 52: 97-98.

Crane, M.B., R. M. Greenslade, A. M. Massee, and H. M. Tydeman

1936. Studies on the resistance and immunity of apples to the woolly apple aphis, Eriosoma lanigerum (Hausm.). Jour. Pomol. 14(2): 137-163.

Dumbleton, L. J., and F. J. JeFFREYS

1938. The control of the woolly aphis by Aphelinus mali. New Zealand Jour. Sci. Tech. $20(3 \mathrm{~A}): 183 \mathrm{~A}-190 \mathrm{~A}$.

Essig, E. O.

1942. Woolly apple aphid infesting apple cores. Jour. Econ. Ent. 35(2): 281.

FrogGatT, Walter W.

1903. Woolly aphis, or American blight. Agr. Gaz. New South Wales 14(1): 18-25. 
Garman, Philip, and J. F. Townsend

1952. Control of apple insects. Connecticut Agr. Exp. Sta. Bul. 552: 12-13.

Heriot, A. D.

1938. Biological and morphological differences between Eriosoma crataegi (Oestlund) and Eriosoma lanigera (Haus.). Ent. Soc. British Columbia Proc. 34, 1937: 22-32.

LOHRENZ, H.W.

1911. The woolly aphis, Schizoneura lanigera. Jour. Eicon. Ent. 4(2): 162-180.

Madsen, Harold F., ARthur D. Borden, and Edward C. Koch

1954. Two major pests on apples. California Agr. 8(6): 14.

Madsen, Harold F., and Stanley C. Hoyt

1957. The effects of spray chemicals on local dispersal of woolly apple aphid. Jour. Econ. Ent. 50(4) : 402-406.

MARCOVITCH, $\mathrm{S}$.

1934. The woolly apple aphid in Tennessee. Tennessee Agr. Exp. Sta. Bul. 151: 1-16. Palmer, Miriam A.

1952. Aphids of the Rocky Mountain region. Thomas Say Foundation, Lafayette, Indiana. $452 \mathrm{pp}$.

PATCH, EDITH M.

1912. Elm leaf curl and woolly apple aphid. Maine Agr. Exp. Sta. Bull. 203: 235-258.

1913. Woolly aphid of the apple. Maine Agr. Exp. Sta. Bul. 217: 173-188.

1938. Food plant catalog of aphids. Maine Agr. Exp. Sta. Bul. 393: 1-431.

Schoene, W. J. and G. W. UNDERHILL

1935. Life history and migration of the apple woolly aphis. Virginia Agr. Exp. Sta. Tech. Bul. 57: 1-31.

Theobald, Fred V.

1920. The woolly aphid of the apple and elm. Jour. Pomol. 2(1) : 73-92.

Venables, E. P.

1929. Observations on the woolly aphis of the apple. Ent. Soc. British Columbia Proc. 26: $28-33$. 

The journal Hilgardia is published at irregular intervals, in volumes of about 600 pages. The number of issues per volume varies.

Subscriptions are not sold. The periodical is sent as published only to libraries, or to institutions in foreign countries having publications to offer in exchange.

You may obtain a single copy of any issue free, as long as the supply lasts; please request by volume and issue number from:
Agricultural Publications
207 University Hall
2200 University A venue
Berkeley 4, California

The limit to nonresidents of California is 10 separate issues on a single order. A list of the issues still available will be sent on request. 